\title{
1 Parameter Estimation of a Six-Lump Kinetic Model of an 2 Industrial Fluid Catalytic Cracking Unit
}

3 Yakubu M. John ${ }^{\text {a }}$, Mustafa A. Mustafa ${ }^{\text {b }}$, Raj Patel ${ }^{\mathrm{a}}$, Iqbal M. Mujtaba ${ }^{\mathrm{a} *}$

$4{ }^{a}$ Chemical Engineering Division, School of Engineering, University of Bradford, Bradford, $5 \quad B D 71 D P, U K$

$6{ }^{b}$ Department of Chemical Engineering, Faculty of Engineering, University of Khartoum, 7 Sudan

$8 \quad$ * I.M.Mujtaba@bradford.ac.uk

10 Abstract

11 In this work a simulation of detailed steady state model of an industrial fluid catalytic 12 cracking (FCC) unit with a newly proposed six-lumped kinetic model which cracks gas oil 13 into diesel, gasoline, liquefied petroleum gas (LPG), dry gas and coke. Frequency factors, 14 activation energies and heats of reaction for the catalytic cracking kinetics and a number of 15 model parameters were estimated using a model based parameter estimation technique along 16 with data from an industrial FCC unit in Sudan. The estimated parameters were used to predict the major riser fractions; diesel as $0.1842 \mathrm{~kg}$-lump $/ \mathrm{kg}$-feed with a $0.81 \%$ error while gasoline as $0.4863 \mathrm{~kg}$-lump/kg-feed with a $2.71 \%$ error compared with the plant data. Thus, with good confidence, the developed kinetic model is able to simulate any type of FCC riser with six-lump model as catalyst-to-oil $(\mathrm{C} / \mathrm{O})$ ratios were varied and the results predicted the typical riser profiles.

Keyword: FCC riser; modelling and simulation; six-lumped model; parameter estimation.

\section{1. Introduction}

As demand for heavy crude has decreased over the last decade, the demand for lighter end fractions, such as diesel, gasoline and olefins, have consequently increased. The FCC unit converts gas oil, with high boiling point petroleum fractions, into the much essential transportation fuels such as gasoline, diesel and jet fuel (Sadeghbeigi, 2000). This is to increase the refinery output of consumable/sellable products and meet demand, which would

30 in turn maximise the profits of the refinery. 
The conventional FCC unit is made up of the riser for cracking reaction and the regenerator for catalyst regeneration (John et al., 2017b, John et al., 2017a, Sadeghbeigi, 2000, Han and Chung, 2001a). When the gas oil is atomized with dispersed steam on the surface of the catalyst at the vaporization section of the riser, it vaporizes instantaneously and the bulk fluid moves pneumatically upward into the riser where the hydrocarbon vapour breaks down into lighter products as it journeys upward with the hot catalyst. As a result, coke, a by-product of the reaction, is deposited on the surface and pores of the catalyst thus, deactivating it. The cracked products are separated into catalyst and vapour in the disengaging section with the use of cyclones. While the vapour goes to the fractionators for further separation, the deactivated catalyst flows into the regenerator through the stripping section, where the coke deposited on catalyst is burnt off rendering the catalyst sufficiently hot and activated or regenerated. The hot regenerated catalyst is returned continuously to the riser reactor for continuous cracking reactions, which supplies the heat responsible for endothermic cracking reactions. This continuous catalyst circulation is possible because of both heat generation and consumption during chemical reactions along with the unit's hydrodynamic balance.

The heat balance of the FCC unit, a major influence of the hydrodynamics of the process, depends on the endothermic heats of the cracking reactions (Arbel et al., 1995) and needs to be adequately measured. During regeneration, heat produced compensates the heat necessary for the endothermic cracking reactions, resulting in the FCC unit operating under conditions of thermal balance (Arandes et al., 2000). These conditions of thermal balance are influenced by the heat from the feed, the vaporization steam, regenerated catalyst and the endothermic reactions in the riser. Most of the heat components are measureable with less difficulty compared with the heat produced or consumed during the endothermic reactions. To account for the endothermic heat of reactions, it is necessary to measure the enthalpy of reaction in the riser, which is important for the effective control, and stability of the FCC unit.

Many riser models of FCC unit found in the literature do not use equations that account for the endothermic heat of reaction in the riser. At best, the temperature profile of the gas phase is presented. A real industrial plant located in Sudan is simulated in this work. It has five products and a feed, making it a six lumped kinetic model; they are gas oil, diesel, gasoline, liquefied natural gas (LPG), dry gas and coke. To simulate this industrial FCC unit, a six

61 lumped kinetic model that adequately represents its product distribution is required. 62 However, this six lumped kinetic model is unique and not readily used in the literature. Where this six lumped kinetic model was used (Du et al., 2014, Xiong et al., 2015, Zhang et 
al., 2017), the riser model did not account for the heat of reaction, which is the endothermic heat required for the cracking of the feed. This heat of reaction is important and a requirement for the riser model used in this work (Han and Chung, 2001a, Han and Chung, 2001b). This six-lumped kinetic model (Du et al., 2014, Xiong et al., 2015, Zhang et al., 2017) have their frequency factors and activation energies presented in the literature. However, they did not provide their enthalpies; hence, the data they used cannot be used to account for the endothermic heat of reaction. In this work, the endothermic heat of reaction will be calculated using a similar but new six lump kinetic reaction scheme which incorporates the new enthalpies of reaction, frequency factors and activation energies obtained through parameter estimation technique in gPROMS. These new estimated parameters will make it possible for the simulation of the FCC unit in Sudan using the robust riser model of Han et al., (2011a, b) and account for the endothermic heat of reaction.

Hence, in this work, the FCC unit simulation model of Han et al., (2011a, b) is used on gPROMS software for parameter estimation to estimate activation energies, frequency factors and enthalpies of a new riser cracking reactions scheme of an industrial FCC plant located in Sudan. This new and comprehensive kinetic model and parameters of the reaction scheme of the industrial plant in Sudan can be used to simulate other FCC units with similar product distribution.

\subsection{Kinetic modelling and model parameters}

The FCC is a significant unit that has drawn the attention of many researchers. However, little achievements have been made when it comes to the accurate understanding of the riser unit behaviour. This could be due to the complexity of the riser's feed which is a complex mixture of extremely large number of unknown compounds. Also, there is the complex hydrodynamics of the riser owing to the three phases (solid, liquid and gas) nature along with gas phase volume expansion due to vaporization and cracking reaction (Kumar and Reddy, 2011). The challenge with the cracking reaction is its characterization. Most research efforts to model cracking kinetics consider components with similar characteristics as a single lump and each lump is considered unique. There are three kinds of such lumping strategy. The first is the parametric strategy that considers a lump, being the feed, which cracks into some lumps such as gasoline, gas and coke as products of cracking reactions (Theologos and Markatos, 1993, Jacob et al., 1976). The second type of lumping strategy is pseudo-cracking where the feedstock and products are considered to be a mixture of some hypothetical or pseudo components (Bollas et al., 2004, Gupta et al., 2007) giving rise to many lumps. The 
third is the structure oriented lumping, which offers a basis for molecular based modelling of all refinery processes. It creates reaction networks of varying sizes and difficulties and treats hydrocarbon molecules as structures that builds continually (Quann and Jaffe, 1992). Although each strategy has its advantage and disadvantage, the lumping strategy has gained acceptability in the characterization of reactants and products from the cracking reactions in the FCC unit, with different number of lumps used by different researchers.

The 3-lump kinetic model (Weekman, 1968) was the first to be presented, where gas oil was cracked into two other lumps; gasoline and gases plus coke. Coke is useful when burnt in the regenerator to provide the heat required for the cracking reactions in the riser, hence, the 3lump model was further broken to form the 4-lump model (Lee et al., 1989). The 4-lump model includes gas oil, gasoline, gases and coke. Further increment of lumps were added to acquire more detail and to achieve a higher level of accuracy in the lumping strategy. This led to the development of several lumps and although the number of lumps may be the same, the nature of lumps may be different. For instance, the six-lump model of Souza et al., (2011) is different from the six-lump model of $\mathrm{Mu}$ et al. (2005). The increase in number of lumps continued to the 5-lump model (Dupain et al., 2003, Jorge Ancheyta Juarez, 1999); the 6Lump model (Takatsuka et al., 1987, Du et al., 2014, Xiong et al., 2015, Zhang et al., 2017); 7-lump model (Heydari et al., 2010, Xu et al., 2006); 8-lump model (Gao et al., 2014, Hagelberg et al., 2002); 9-lump model (You, 2013, You et al., 2006); 10-lump model (Jacob et al., 1976); 11 lump model (Mao et al., 1985, Sa et al., 1985, Zhu et al., 1985) and so on. In this work, new kinetic parameters are developed for a new six-lump model.

\subsection{Six-lump model}

Although several six-lump models have been used in the modelling of the FCC unit kinetic reactions, all have their unique characteristics. A six lump kinetic model (Baldessar and Negrão, 2005, Souza et al., 2011) was used that cracks gasoil into gasoline, LPG, fuel gas, light cycle oil (LCO) and coke lumps. Mu et al. (2005) presented a different six-lump model; it cracks residual fuel oil (RFO) into heavy fuel oil (HFO), light fuel oil (LFO), gasoline, gas and coke. Besides the fact that their product distributions are different, their respective frequency factors and activation energies are different and were presented (Mu et al., 2005) without the heat of reaction for each cracking reaction. Hence, these kinetic models may not be suitable for use with the comprehensive model (Han and Chung, 2001a, Han and Chung, 2001b) of FCC unit used in this study. Another six-lump model, which is similar and presented the same lumps as the one developed in this work was presented in the literature 
130 (Xiong et al., 2015, Du et al., 2014, Zhang et al., 2017), the difference being the secondary 131 cracking reactions of LPG and dry gas into coke. This difference is significant because many authors assume that the cracking reactions of some lumps into others lumps can be neglected

133 to reduce the total number of kinetic parameters to be accounted for. However, with a 134 powerful tool that performs accurate parameter estimation, all parameters can be estimated, 135 and the data can then be subjected to the decision of whether to neglect some reactions or not. 136 Therefore, the new kinetic model accounts for kinetic data for the secondary cracking 137 reactions of LPG and dry gas into coke. Again, only kinetic data such as the frequency factors 138 and activation energies are presented (Du et al., 2014, Xiong et al., 2015, Zhang et al., 2017) 139 without the heat of reactions of the kinetic equations involved, which are required by the riser 140 model used in this study. The six-lump kinetic model developed in this work cracks gas oil 141 into diesel, gasoline, LPG, dry gas and coke. It estimates the heat of reactions involved in the 142 six-lump cracking reactions and presents kinetic data (frequency factors, activation energies 143 and heats of reaction) for the secondary reactions of the conversion of LPG and dry gas into 144 coke. Figure 1 shows a schematic diagram of the kinetic model presented by Du et al., 145 (2014), Xiong et al (2015) and Zhang et al. (2017), even though Xiong et al (2015) did not 146 present the secondary cracking of LPG to dry gas, while Figure 2 shows the proposed kinetic 147 model to be used in this work. As stated earlier, the difference between Figures 1 and 2 is the 148 secondary cracking reactions of LPG and dry gas into coke.

149

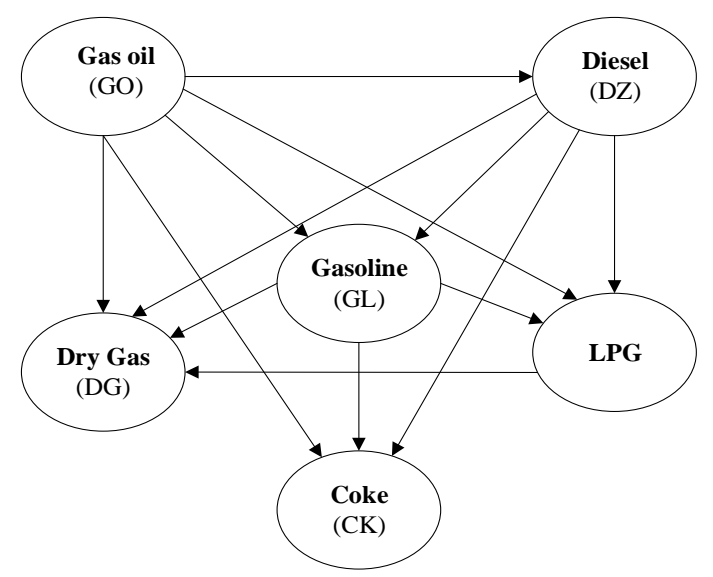

150 Figure 1. Six-lump kinetic model (Du et al., 2014, Xiong et al., 2015, Zhang et al., 2017) 
151

152 Figure 2. Six-lump kinetic model as proposed in this work

\section{2. The Riser Model}

154 A typical configuration of a FCC process consist of two major units; the riser and regenerator 155 156

157

160 The FCC riser is modelled as a one-dimensional plug flow reactor without axial and radial 161 dispersion. It was established that the one dimensional model is capable of predicting the 162 overall performance of the riser (Theologos and Markatos, 1993), hence it can be adequate 163 for the parameter estimation in this work. The regenerated catalyst meets gas oil and 164 vaporizes almost immediately into the riser moving pneumatically upward. This leads to a 165 cracking reaction on catalyst surface to form valuable fuels such as diesel, gasoline, LPG, dry 166 gas and coke. The industrial riser considered in this work is $47.1 \mathrm{~m}$ in height and $1.36 \mathrm{~m}$ in 167 diameter.

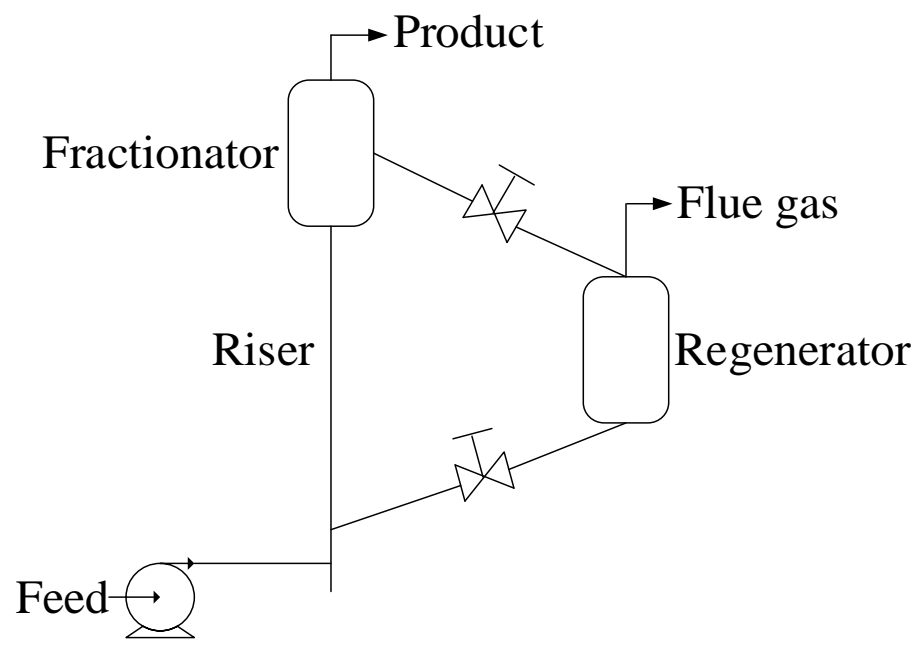

Figure 3. A schematic diagram of the RFCC unit 
168 The riser simulation model combines mass, energy and momentum balance equations for the catalyst and the gaseous phases based on the following assumptions:

170 1. The hydrocarbon feed instantly vaporizes as it comes into contact with the hot catalyst from the regenerator, then moves upward in thermal equilibrium with the catalyst and there is no loss of heat from the riser (Ali et al., 1997).

2. The cracking reactions only take place in the riser and on the catalyst surface. The reactions are assumed fast enough to justify steady state operation.

3. The rates of dispersion and adsorption inside the catalyst particles are negligible.

Some model equations along with some of their parameters used in this simulation study were adopted from literature (Han and Chung, 2001a, Han and Chung, 2001b, John et al., 2017a, John et al., 2017b). The feed conditions and other parameters were obtained from an industrial refinery from Sudan and presented in Appendix Table A.3. Material balance equations for the various lumps showing the six-lump; gas oil, diesel, gasoline, LPG, dry gas and coke are represented by Equations (15-20). The overall rates of reaction for the six lumps: gas oil $\mathrm{R}_{\mathrm{go}}$, diesel $\mathrm{R}_{\mathrm{gdz}}$, gasoline $\mathrm{R}_{\mathrm{gl}}$, $\mathrm{LPG} \mathrm{R}_{\mathrm{lpg}}$, dry gas $\mathrm{R}_{\mathrm{dg}}$, and coke $\mathrm{R}_{\mathrm{ck}}$, were developed from the six-lump kinetic reaction scheme and are presented in Equations (21-26). These equations are new six lumped model equations since they include the secondary reactions of the cracking of LPG and dry gas to coke which were not in the literature. Each overall rate of reaction is a function of an overall rate constant that is described by the Arrhenius equation given in Equations (27-41), which include the new overall rate constants of the secondary reactions of the cracking of LPG and dry gas to coke. During the catalytic cracking, endothermic heat from the regenerator is utilized in the riser, and the rate of heat removal by reaction, $Q_{\text {react }}$, is estimated by Equation 42, a unique feature of the current riser model used in this study. Equations (43 and 44) are derived from the energy balance of the riser showing the temperature of catalyst and gas phases. The equations that govern the hydrodynamics of the riser are described in Equations (45-59), with Equations (55-56) describing the momentum balance equations, which gives the catalyst and gas velocity distributions across the riser. The gas volume fraction, $\varepsilon_{\mathrm{g}}$, and catalyst volume fraction, $\varepsilon_{\mathrm{c}}$, are obtained from Equation 45. They give a hydrodynamic constraint such that, the summation of the volume fractions add up to unity. Equation (51), the riser pressure, is obtained from the simple ideal gas relationship but well accounted for with $\mathrm{Z}$ as the compressibility factor (Equation 70). Equations (1-14) are riser model equations for four 
201 lumped kinetic model used in this work to demonstrate the capability of the parameter estimation technique to predict the right kinetic parameters.

203 The riser model equations are a set of nonlinear and algebraic equations and gPROMS is used

204 for the solution. gPROMS is a general process modelling system for simulation, optimisation 205 and control (both steady state and dynamic) of highly complex processes such as the FCC 206 unit riser. It is an equation oriented software and all solvers have been designed specifically 207 for large-scale systems such as the FCC unit with no restrictions regarding problem size other 208 than those imposed by available machine memory (Mujtaba, 2012). In spite of the robustness 209 of gPROMS, there are just a few known literature on the use of the software to solve the 210 models of the FCC unit. These (John et al., 2017a, John et al., 2017b, John et al., 2017c, 211 Jarullah et al., 2017) are the first attempts and gPROMS proves to be a reliable software. The 212 riser model is constructed in the model section and the parameters are specified in the process 213 section of the gPROMS software 4.2.0. The gPROMS software is capable of analysing the set 214 of equations to determine the stiffness of the system and calls on the appropriate solvers, in 215 this case, solvers capable of solving the nonlinear system of equations of the riser model and 216 perform adequate parameter estimation. 
Table 1: Equations and descriptions

\begin{tabular}{|c|c|c|}
\hline Description of variable & Equations & Eq.No \\
\hline \multicolumn{3}{|c|}{ Kinetic model equations for the four-lumped model (Han and Chung, 2001a, Han and Chung, 2001b) } \\
\hline $\begin{array}{l}\text { Gas oil fractional yield along the riser } \\
\text { height }\end{array}$ & $\frac{\mathrm{d}_{\mathrm{g}_{\mathrm{go}}}}{\mathrm{dx}}=\frac{\rho_{\mathrm{c}} \varepsilon_{\mathrm{c}} \Omega}{\mathrm{F}_{\mathrm{g}}} \mathrm{R}_{\mathrm{go}}$ & (1) \\
\hline $\begin{array}{l}\text { Gasoline fractional yield along the riser } \\
\text { height }\end{array}$ & $\frac{\mathrm{d}_{\mathrm{y}_{\mathrm{gl}}}}{\mathrm{dx}}=\frac{\rho_{\mathrm{c}} \varepsilon_{\mathrm{c}} \Omega}{\mathrm{F}_{\mathrm{g}}} \mathrm{R}_{\mathrm{gl}}$ & (2) \\
\hline $\begin{array}{l}\text { Light gas fractional yield along the riser } \\
\text { height }\end{array}$ & $\frac{\mathrm{d}_{\mathrm{ygs}_{\mathrm{gs}}}}{\mathrm{dx}}=\frac{\rho_{\mathrm{c}} \varepsilon_{\mathrm{c}} \Omega}{\mathrm{F}_{\mathrm{g}}} \mathrm{R}_{\mathrm{gs}}$ & (3) \\
\hline Coke fractional yield along the riser height & $\frac{\mathrm{d}_{\mathrm{y}_{\mathrm{ck}}}}{\mathrm{dx}}=\frac{\rho_{\mathrm{c}} \varepsilon_{\mathrm{c}} \Omega}{\mathrm{F}_{\mathrm{g}}} \mathrm{R}_{\mathrm{ck}}$ & (4) \\
\hline Rates of reaction for gas oil $\mathrm{R}_{\mathrm{Go}}$ & $\mathrm{R}_{\mathrm{go}}=-\left(\mathrm{k}_{1}+\mathrm{k}_{2}+\mathrm{k}_{3}\right) \mathrm{y}_{\mathrm{go}}{ }^{2} \emptyset_{\mathrm{c}}$ & (5) \\
\hline Rates of reaction for gasoline $\mathrm{R}_{\mathrm{Gl}}$ & $\mathrm{R}_{\mathrm{gl}}=\left(\mathrm{k}_{1} \mathrm{y}_{\mathrm{go}}{ }^{2}-\mathrm{k}_{4} \mathrm{y}_{\mathrm{gl}}-\mathrm{k}_{5} \mathrm{y}_{\mathrm{gl}}\right) \emptyset_{\mathrm{c}}$ & (6) \\
\hline Rates of reaction for light gas $\mathrm{R}_{\mathrm{Gs}}$ & $\mathrm{R}_{\mathrm{gs}}=\left(\mathrm{k}_{2} \mathrm{y}_{\mathrm{go}}{ }^{2}-\mathrm{k}_{4} \mathrm{y}_{\mathrm{gl}}\right) \emptyset_{\mathrm{c}}$ & (7) \\
\hline Rates of reaction for coke $R_{C k}$ & $\mathrm{R}_{\mathrm{ck}}=\left(\mathrm{k}_{3} \mathrm{y}_{\mathrm{go}}{ }^{2}-\mathrm{k}_{5} \mathrm{y}_{\mathrm{gl}}\right) \emptyset_{\mathrm{c}}$ & (8) \\
\hline $\begin{array}{l}\text { Overall rate constants for cracking gas oil } \\
\text { to gasoline }\end{array}$ & $\mathrm{k}_{1}=\mathrm{k}_{10} \exp \left(\frac{-\mathrm{E}_{1}}{\mathrm{R}_{g} \mathrm{~T}_{\mathrm{g}}}\right)$ & (9) \\
\hline $\begin{array}{l}\text { Overall rate constants for cracking gas oil } \\
\text { to gases }\end{array}$ & $\mathrm{k}_{2}=\mathrm{k}_{20} \exp \left(\frac{-\mathrm{E}_{2}}{\mathrm{R}_{g} \mathrm{~T}_{\mathrm{g}}}\right)$ & $(10)$ \\
\hline $\begin{array}{l}\text { Overall rate constants for cracking gas oil } \\
\text { to coke }\end{array}$ & $\mathrm{k}_{3}=\mathrm{k}_{30} \exp \left(\frac{-\mathrm{E}_{3}}{\mathrm{R}_{g} \mathrm{~T}_{\mathrm{g}}}\right)$ & $(11)$ \\
\hline
\end{tabular}




\begin{tabular}{|c|c|c|}
\hline $\begin{array}{l}\text { Overall rate constants for cracking gasoline } \\
\text { to gases }\end{array}$ & $\mathrm{k}_{4}=\mathrm{k}_{40} \exp \left(\frac{-\mathrm{E}_{4}}{\mathrm{R}_{g} \mathrm{~T}_{\mathrm{g}}}\right)$ & $(12)$ \\
\hline $\begin{array}{l}\text { Overall rate constants for cracking gasoline } \\
\text { to coke }\end{array}$ & $\mathrm{k}_{5}=\mathrm{K}_{50} \exp \left(\frac{-\mathrm{E}_{5}}{\mathrm{R}_{g} \mathrm{~T}_{\mathrm{g}}}\right)$ & (13) \\
\hline $\begin{array}{l}Q_{\text {React }} \text { is the rate of heat generation or heat } \\
\text { removal by reaction }\end{array}$ & $\mathrm{Q}_{\text {react }}=-\left(\Delta \mathrm{H}_{1} \mathrm{k}_{1} \mathrm{y}_{\mathrm{go}}{ }^{2}+\Delta \mathrm{H}_{2} \mathrm{k}_{2} \mathrm{y}_{\mathrm{go}}{ }^{2}+\Delta \mathrm{H}_{3} \mathrm{k}_{3} \mathrm{y}_{\mathrm{go}}{ }^{2}+\Delta \mathrm{H}_{4} \mathrm{k}_{4} \mathrm{y}_{\mathrm{gl}}+\Delta \mathrm{H}_{5} \mathrm{k}_{5} \mathrm{y}_{\mathrm{gl}}\right) \emptyset_{\mathrm{c}}$ & $(14)$ \\
\hline \multicolumn{3}{|c|}{ Kinetic model equations for the six-lump model developed in this work } \\
\hline $\begin{array}{l}\text { Gas oil fractional yield along the riser } \\
\text { height }\end{array}$ & $\frac{\mathrm{d}_{\mathrm{ygo}_{\mathrm{go}}}}{\mathrm{dx}}=\frac{\rho_{\mathrm{c}} \varepsilon_{\mathrm{c}} \Omega}{\mathrm{F}_{\mathrm{g}}} \mathrm{R}_{\mathrm{go}}$ & $(15)$ \\
\hline $\begin{array}{l}\text { Diesel fractional yield along the riser } \\
\text { height }\end{array}$ & $\frac{\mathrm{d}_{\mathrm{y}_{\mathrm{dz}}}}{\mathrm{dx}}=\frac{\rho_{\mathrm{c}} \varepsilon_{\mathrm{c}} \Omega}{\mathrm{F}_{\mathrm{g}}} \mathrm{R}_{\mathrm{dz}}$ & $(16)$ \\
\hline $\begin{array}{l}\text { Gasoline fractional yield along the riser } \\
\text { height }\end{array}$ & $\frac{\mathrm{d}_{\mathrm{ygl}_{\mathrm{gl}}}}{\mathrm{dx}}=\frac{\rho_{\mathrm{c}} \varepsilon_{\mathrm{c}} \Omega}{\mathrm{F}_{\mathrm{g}}} \mathrm{R}_{\mathrm{gl}}$ & $(17)$ \\
\hline LPG fractional yield along the riser height & $\frac{\mathrm{d}_{\mathrm{y}_{\mathrm{lpg}}}}{\mathrm{dx}}=\frac{\rho_{\mathrm{c}} \varepsilon_{\mathrm{c}} \Omega}{\mathrm{F}_{\mathrm{g}}} \mathrm{R}_{\mathrm{lpg}}$ & $(18)$ \\
\hline $\begin{array}{l}\text { Dry gas fractional yield along the riser } \\
\text { height }\end{array}$ & $\frac{\mathrm{d}_{\mathrm{y}_{\mathrm{dg}}}}{\mathrm{dx}}=\frac{\rho_{\mathrm{c}} \varepsilon_{\mathrm{c}} \Omega}{\mathrm{F}_{\mathrm{g}}} \mathrm{R}_{\mathrm{dg}}$ & $(19)$ \\
\hline Coke fractional yield along the riser height & $\frac{\mathrm{d}_{\mathrm{y}_{\mathrm{ck}}}}{\mathrm{dx}}=\frac{\rho_{\mathrm{c}} \varepsilon_{\mathrm{c}} \Omega}{\mathrm{F}_{\mathrm{g}}} \mathrm{R}_{\mathrm{ck}}$ & $(20)$ \\
\hline Overall rate of reaction for gas oil $\mathrm{R}_{\mathrm{go}}$ & $\mathrm{R}_{\mathrm{go}}=-\left(\mathrm{k}_{\mathrm{go}-\mathrm{dz}}+\mathrm{k}_{\mathrm{go}-\mathrm{g}}+\mathrm{k}_{\mathrm{go}-\mathrm{ck}}+\mathrm{k}_{\mathrm{go}-\mathrm{lpg}}+\mathrm{k}_{\mathrm{go}-\mathrm{dg}}\right) \mathrm{y}_{\mathrm{go}}{ }^{2} \emptyset_{\mathrm{c}}$ & $(21)$ \\
\hline Overall rate of reaction for gasoline $R_{d z}$ & $\mathrm{R}_{\mathrm{dz}}=\left(\left(\mathrm{k}_{\mathrm{go}-\mathrm{dz}} \mathrm{y}_{\mathrm{go}}^{2}\right)-\left(\mathrm{k}_{\mathrm{dz}-\mathrm{ck}}+\mathrm{k}_{\mathrm{dz}-\mathrm{gl}}+\mathrm{k}_{\mathrm{dz}-\mathrm{lpg}}+\mathrm{k}_{\mathrm{dz}-\mathrm{dg}}\right) \mathrm{y}_{\mathrm{dz}}\right) \emptyset_{\mathrm{c}}$ & $(22)$ \\
\hline
\end{tabular}




\begin{tabular}{|c|c|c|}
\hline Overall rate of reaction for gasoline $\mathrm{R}_{\mathrm{Gl}}$ & $\mathrm{R}_{\mathrm{gl}}=\left(\mathrm{k}_{\mathrm{go}-\mathrm{g}} \mathrm{y}_{\mathrm{go}}{ }^{2}-\mathrm{k}_{\mathrm{dz}-\mathrm{gl}} \mathrm{y}_{\mathrm{dz}}-\left(\mathrm{k}_{\mathrm{gl}-\mathrm{lpg}}+\mathrm{k}_{\mathrm{gl}-\mathrm{dg}}+\mathrm{k}_{\mathrm{gl}-\mathrm{ck}}\right) \mathrm{y}_{\mathrm{gl}}\right) \emptyset_{\mathrm{c}}$ & (23) \\
\hline Overall rate of reaction for light gas $\mathrm{R}_{\mathrm{lpg}}$ & $\mathrm{R}_{\mathrm{lpg}}=\left(\mathrm{k}_{\mathrm{go}-\mathrm{lpg}} \mathrm{y}_{\mathrm{go}}{ }^{2}+\mathrm{k}_{\mathrm{dz}-\mathrm{lpg}} \mathrm{y}_{\mathrm{dz}}+\mathrm{k}_{\mathrm{gl}-\mathrm{lpg}} \mathrm{y}_{\mathrm{gl}}-\left(\mathrm{k}_{\mathrm{lpg}-\mathrm{dg}}+\mathrm{k}_{\mathrm{lpg}-\mathrm{ck}}\right) \mathrm{y}_{\mathrm{lgp}}\right) \emptyset_{\mathrm{c}}$ & (24) \\
\hline Overall rate of reaction for light gas $\mathrm{R}_{\mathrm{dg}}$ & $\mathrm{R}_{\mathrm{dg}}=\left(\mathrm{k}_{\mathrm{go}-\mathrm{dg}} \mathrm{y}_{\mathrm{go}}{ }^{2}+\mathrm{k}_{\mathrm{dz}-\mathrm{dg}} \mathrm{y}_{\mathrm{dz}}+\mathrm{k}_{\mathrm{gl}-\mathrm{dg}} \mathrm{y}_{\mathrm{gl}}+\mathrm{k}_{\mathrm{lpg}-\mathrm{dg}} \mathrm{y}_{\mathrm{lpg}}-\mathrm{k}_{\mathrm{dg}-\mathrm{ck}} \mathrm{y}_{\mathrm{dg}}\right) \emptyset_{\mathrm{c}}$ & (25) \\
\hline Overall rate of reaction for coke $\mathrm{R}_{\mathrm{ck}}$ & $\mathrm{R}_{\mathrm{ck}}=\left(\mathrm{k}_{\mathrm{go}-\mathrm{ck}} \mathrm{y}_{\mathrm{go}}{ }^{2}+\mathrm{k}_{\mathrm{dz}-\mathrm{ck}} \mathrm{y}_{\mathrm{dz}}+\mathrm{k}_{\mathrm{gl}-\mathrm{ck}} \mathrm{y}_{\mathrm{gl}}+\mathrm{k}_{\mathrm{lpg}-\mathrm{ck}} \mathrm{y}_{\mathrm{lpg}}-\mathrm{k}_{\mathrm{dg}-\mathrm{ck}} \mathrm{y}_{\mathrm{dg}}\right) \emptyset_{\mathrm{c}}$ & (26) \\
\hline $\begin{array}{l}\text { Overall rate constants for cracking gas oil } \\
\text { to diesel }\end{array}$ & $\mathrm{k}_{\mathrm{go}-\mathrm{dz}}=\mathrm{k}_{0_{\mathrm{go}-\mathrm{dz}}} \exp \left(\frac{-\mathrm{E}_{\mathrm{go}-\mathrm{dz}}}{\mathrm{R}_{\mathrm{g}} \mathrm{T}_{\mathrm{g}}}\right)$ & (27) \\
\hline $\begin{array}{l}\text { Overall rate constants for cracking gas oil } \\
\text { to gasoline }\end{array}$ & $\mathrm{k}_{\mathrm{go}-\mathrm{gl}}=\mathrm{k}_{0_{\mathrm{go}-\mathrm{gl}}} \exp \left(\frac{-\mathrm{E}_{\mathrm{go}-\mathrm{gl}}}{\mathrm{R}_{g} \mathrm{~T}_{\mathrm{g}}}\right)$ & (28) \\
\hline $\begin{array}{l}\text { Overall rate constants for cracking gas oil } \\
\text { to LPG }\end{array}$ & $\mathrm{k}_{\text {go-lpg }}=\mathrm{k}_{0_{\text {go-lpg }}} \exp \left(\frac{-\mathrm{E}_{\text {go-lpg }}}{\mathrm{R}_{g} \mathrm{~T}_{\mathrm{g}}}\right)$ & (29) \\
\hline $\begin{array}{l}\text { Overall rate constants for cracking gas oil } \\
\text { to dry gas }\end{array}$ & $\mathrm{k}_{\mathrm{go}-\mathrm{dg}}=\mathrm{k}_{0_{\mathrm{go}-\mathrm{dg}}} \exp \left(\frac{-\mathrm{E}_{\mathrm{go}-\mathrm{dg}}}{\mathrm{R}_{g} \mathrm{~T}_{\mathrm{g}}}\right)$ & (30) \\
\hline $\begin{array}{l}\text { Overall rate constants for cracking gas oil } \\
\text { to coke }\end{array}$ & $\mathrm{k}_{\mathrm{go}-\mathrm{ck}}=\mathrm{k}_{0_{\mathrm{go}-\mathrm{ck}}} \exp \left(\frac{-\mathrm{E}_{\mathrm{go}-\mathrm{ck}}}{\mathrm{R}_{\mathrm{g}} \mathrm{T}_{\mathrm{g}}}\right)$ & (31) \\
\hline $\begin{array}{l}\text { Overall rate constants for cracking diesel } \\
\text { to gasoline }\end{array}$ & $\mathrm{k}_{\mathrm{dz}-\mathrm{gl}}=\mathrm{k}_{0_{\mathrm{dz}-\mathrm{gl}}} \exp \left(\frac{-\mathrm{E}_{\mathrm{dz}-\mathrm{gl}}}{\mathrm{R}_{g} \mathrm{~T}_{\mathrm{g}}}\right)$ & (32) \\
\hline $\begin{array}{l}\text { Overall rate constants for cracking diesel } \\
\text { to } L P G\end{array}$ & $\mathrm{k}_{\mathrm{dz}-\mathrm{lpg}}=\mathrm{k}_{0_{\mathrm{dz}-\mathrm{lpg}}} \exp \left(\frac{-\mathrm{E}_{\mathrm{dz}-\mathrm{lpg}}}{\mathrm{R}_{g} \mathrm{~T}_{\mathrm{g}}}\right)$ & (33) \\
\hline $\begin{array}{l}\text { Overall rate constants for cracking diesel } \\
\text { to dry gas }\end{array}$ & $\mathrm{k}_{\mathrm{dz}-\mathrm{dg}}=\mathrm{k}_{0_{\mathrm{dz}-\mathrm{dg}}} \exp \left(\frac{-\mathrm{E}_{\mathrm{dz}-\mathrm{dg}}}{\mathrm{R}_{g} \mathrm{~T}_{\mathrm{g}}}\right)$ & (34) \\
\hline
\end{tabular}




\begin{tabular}{|l|l|l|}
\hline $\begin{array}{l}\text { Overall rate constants for cracking diesel } \\
\text { to coke }\end{array}$ & $\mathrm{k}_{\mathrm{dz}-\mathrm{ck}}=\mathrm{k}_{0_{\mathrm{dz}-\mathrm{ck}}} \exp \left(\frac{-\mathrm{E}_{\mathrm{dz}-\mathrm{ck}}}{\mathrm{R}_{g} \mathrm{~T}_{\mathrm{g}}}\right)$ & $(35)$ \\
\hline $\begin{array}{l}\text { Overall rate constants for cracking gasoline } \\
\text { to LPG }\end{array}$ & $\mathrm{k}_{\mathrm{gl}-\mathrm{lpg}}=\mathrm{k}_{0_{\mathrm{gl}-\mathrm{lpg}}} \exp \left(\frac{-\mathrm{E}_{\mathrm{gl}-\mathrm{lpg}}}{\mathrm{R}_{\mathrm{g}} \mathrm{T}_{\mathrm{g}}}\right)$ & $(36)$ \\
\hline $\begin{array}{l}\text { Overall rate constants for cracking gasoline } \\
\text { to dry gas }\end{array}$ & $\mathrm{k}_{\mathrm{gl}-\mathrm{dg}}=\mathrm{k}_{0_{\mathrm{gl}-\mathrm{dg}}} \exp \left(\frac{-\mathrm{E}_{\mathrm{gl}-\mathrm{dg}}}{\mathrm{R}_{g} \mathrm{~T}_{\mathrm{g}}}\right)$ & $(37)$ \\
\hline $\begin{array}{l}\text { Overall rate constants for cracking gasoline } \\
\text { to coke }\end{array}$ & $\mathrm{k}_{\mathrm{gl}-\mathrm{ck}}=\mathrm{k}_{0_{\mathrm{gl}-\mathrm{ck}}} \exp \left(\frac{-\mathrm{E}_{\mathrm{gl}-\mathrm{ck}}}{\mathrm{R}_{g} \mathrm{~T}_{\mathrm{g}}}\right)$ & $(38)$ \\
\hline $\begin{array}{l}\text { Overall rate constants for cracking LPG to } \\
\text { dry gas }\end{array}$ & $\mathrm{k}_{\mathrm{lpg}-\mathrm{dg}}=\mathrm{k}_{0_{\mathrm{lpg}-\mathrm{dg}}} \exp \left(\frac{-\mathrm{E}_{\mathrm{lpg}-\mathrm{dg}}}{\mathrm{R}_{g} \mathrm{~T}_{\mathrm{g}}}\right)$ & $(39)$ \\
\hline $\begin{array}{l}\text { Overall rate constants for cracking LPG to } \\
\text { coke }\end{array}$ & $\mathrm{k}_{\mathrm{lpg}-\mathrm{ck}}=\mathrm{k}_{0_{\mathrm{lpg}-\mathrm{ck}}} \exp \left(\frac{-\mathrm{E}_{\mathrm{lpg}-\mathrm{ck}}}{\mathrm{R}_{g} \mathrm{~T}_{\mathrm{g}}}\right)$ \\
\hline $\begin{array}{l}\text { Overall rate constants for cracking dry to } \\
\text { coke }\end{array}$ & $\mathrm{k}_{\mathrm{dg}-\mathrm{ck}}=\mathrm{k}_{0_{\mathrm{dg}-\mathrm{ck}}} \exp \left(\frac{-\mathrm{E}_{\mathrm{dg}-\mathrm{ck}}}{\mathrm{R}_{g} \mathrm{~T}_{\mathrm{g}}}\right)$ & $(40)$ \\
\hline
\end{tabular}




\begin{tabular}{|c|c|c|}
\hline $\begin{array}{l}Q_{\text {React }} \text { is the rate of heat generation or heat } \\
\text { removal by reaction }\end{array}$ & $\begin{aligned} \mathrm{Q}_{\text {react }}=-( & \Delta \mathrm{H}_{\mathrm{go}-\mathrm{dz}} \mathrm{k}_{\mathrm{go}-\mathrm{dz}} \mathrm{y}_{\mathrm{go}}{ }^{2}+\Delta \mathrm{H}_{\mathrm{go}-\mathrm{gl}} \mathrm{k}_{\mathrm{go}-\mathrm{gl}} \mathrm{y}_{\mathrm{go}}{ }^{2}+\Delta \mathrm{H}_{\mathrm{go}-\mathrm{ck}} \mathrm{k}_{\mathrm{go}-\mathrm{ck}} \mathrm{y}_{\mathrm{go}}{ }^{2} \\
& +\Delta \mathrm{H}_{\mathrm{go}-\mathrm{lpg}} \mathrm{k}_{\mathrm{go}-\mathrm{lpg}} \mathrm{y}_{\mathrm{go}}{ }^{2}+\Delta \mathrm{H}_{\mathrm{go}-\mathrm{dg}} \mathrm{k}_{\mathrm{go}-\mathrm{dg}} \mathrm{y}_{\mathrm{go}}{ }^{2} \\
& +\Delta \mathrm{H}_{\mathrm{dz}-\mathrm{ck}} \mathrm{k}_{\mathrm{dz}-\mathrm{ck}} \mathrm{y}_{\mathrm{dz}}+\Delta \mathrm{H}_{\mathrm{dz}-\mathrm{gl}} \mathrm{k}_{\mathrm{dz}-\mathrm{gl}} \mathrm{y}_{\mathrm{dz}} \\
& +\Delta \mathrm{H}_{\mathrm{dz}-\mathrm{lpg}} \mathrm{k}_{\mathrm{dz}-\mathrm{lpg}} \mathrm{y}_{\mathrm{dz}}+\Delta \mathrm{H}_{\mathrm{dz}-\mathrm{dg}} \mathrm{k}_{\mathrm{dz}-\mathrm{dg}} \mathrm{y}_{\mathrm{dz}} \\
& +\Delta \mathrm{H}_{\mathrm{gl}-\mathrm{lpg}} \mathrm{k}_{\mathrm{gl}-\mathrm{lpg}} \mathrm{y}_{\mathrm{gl}}+\Delta \mathrm{H}_{\mathrm{gl}-\mathrm{dg}} \mathrm{k}_{\mathrm{gl}-\mathrm{dg}} \mathrm{y}_{\mathrm{gl}}+\Delta \mathrm{H}_{\mathrm{gl}-\mathrm{ck}} \mathrm{k}_{\mathrm{gl}-\mathrm{ck}} \mathrm{y}_{\mathrm{gl}} \\
& +\Delta \mathrm{H}_{\mathrm{lpg}-\mathrm{dg}} \mathrm{k}_{\mathrm{lpg}-\mathrm{dg}} \mathrm{y}_{\mathrm{lpg}}+\Delta \mathrm{H}_{\mathrm{lpg}-\mathrm{ck}} \mathrm{k}_{\mathrm{lpg}-\mathrm{ck}} \mathrm{y}_{\mathrm{lpg}} \\
& \left.+\Delta \mathrm{H}_{\mathrm{dg}-\mathrm{ck}} \mathrm{k}_{\mathrm{dg}-\mathrm{ck}} \mathrm{y}_{\mathrm{dg}}\right) \emptyset_{\mathrm{c}}\end{aligned}$ & $(42)$ \\
\hline \multicolumn{3}{|l|}{ Riser equations from energy balance equation } \\
\hline $\begin{array}{l}\text { Temperature of catalyst along the riser } \\
\text { height }\end{array}$ & $\frac{\mathrm{dT}_{\mathrm{c}}}{\mathrm{dx}}=\frac{\Omega \mathrm{h}_{\mathrm{p}} \mathrm{A}_{\mathrm{p}}}{\mathrm{F}_{\mathrm{c}} \mathrm{C}_{\mathrm{pc}}}\left(\mathrm{T}_{\mathrm{g}}-\mathrm{T}_{\mathrm{c}}\right)$ & (43) \\
\hline $\begin{array}{l}\text { Temperature of gas phase along the riser } \\
\text { height }\end{array}$ & $\frac{\mathrm{dT}_{\mathrm{g}}}{\mathrm{dx}}=\frac{\Omega}{\mathrm{F}_{\mathrm{g}} \mathrm{C}_{\mathrm{pg}}}\left[\mathrm{h}_{\mathrm{p}} \mathrm{A}_{\mathrm{p}}\left(\mathrm{T}_{\mathrm{c}}-\mathrm{T}_{\mathrm{g}}\right)+\rho_{\mathrm{c}} \varepsilon_{\mathrm{c}} \mathrm{Q}_{\text {react }}\right]$ & $(44)$ \\
\hline \multicolumn{3}{|l|}{ Riser hydrodynamic equations } \\
\hline $\begin{array}{l}\text { Gas volume fraction, } \varepsilon_{\mathrm{g}} \text {, and catalyst } \\
\text { volume fraction, } \varepsilon_{\mathrm{c}}\end{array}$ & $\varepsilon_{\mathrm{c}}=\frac{\mathrm{F}_{\mathrm{c}}}{\mathrm{v}_{\mathrm{c}} \rho_{\mathrm{c}} \Omega} ; \varepsilon_{\mathrm{g}}=1-\varepsilon_{\mathrm{c}}$ & $(45)$ \\
\hline Cross sectional area of the riser & $\Omega=\frac{\pi \mathrm{D}^{2}}{4}$ & $(46)$ \\
\hline Catalyst deactivation & $\emptyset_{c}=\exp \left(-\alpha_{c} C_{c k}\right)$ & (47) \\
\hline Catalyst deactivation coefficient & $\alpha_{\mathrm{c}}=\alpha_{\mathrm{c} 0} \exp \left(\frac{-\mathrm{E}_{\mathrm{c}}}{\mathrm{R}_{g} \mathrm{~T}_{\mathrm{g}}}\right)\left(\mathrm{R}_{\mathrm{AN}}\right)^{\alpha_{\mathrm{c} *}}$ & $(48)$ \\
\hline
\end{tabular}




\begin{tabular}{|c|c|c|}
\hline Coke on catalyst & $\mathrm{C}_{\mathrm{ck}}=\mathrm{C}_{\mathrm{ckCL} 1}+\frac{\mathrm{F}_{\mathrm{g}} \mathrm{y}_{\mathrm{ck}}}{\mathrm{F}_{\mathrm{c}}}$ & (49) \\
\hline Density of the gas phase & $\rho_{\mathrm{g}}=\frac{\mathrm{F}_{\mathrm{g}}}{\varepsilon_{\mathrm{g}} \mathrm{v}_{\mathrm{g}} \Omega}$ & $(50)$ \\
\hline Riser pressure & $\mathrm{P}_{R S}=\rho_{\mathrm{g}} \frac{\mathrm{ZR}_{g} \mathrm{~T}_{\mathrm{g}}}{\mathrm{M}_{\mathrm{wg}}}$ & $(51)$ \\
\hline Catalyst-to-oil ratio $(\mathrm{C} / \mathrm{O})$ & $\mathrm{C} / \mathrm{O}$ ratio $=\frac{\mathrm{F}_{\mathrm{c}}}{\mathrm{F}_{\mathrm{g}}}$ & $(52)$ \\
\hline Pseudo-reduced temperature in the riser & $\mathrm{T}_{\mathrm{pr}}=\frac{\mathrm{T}_{\mathrm{g}}}{\mathrm{T}_{\mathrm{pc}}}$ & (53) \\
\hline Pseudo-reduced pressure in the riser & $\mathrm{P}_{\mathrm{pr}}=\frac{\mathrm{P}_{R S}}{\mathrm{P}_{\mathrm{pc}}}$ & $(54)$ \\
\hline $\begin{array}{l}\text { Catalyst and gas velocity distribution } \\
\text { across the riser }\end{array}$ & $\frac{d v_{c}}{d x}=-\left(G_{c} \frac{\Omega}{F_{c}} \frac{d \varepsilon_{c}}{d x}-\frac{C_{f}\left(v_{g}-v_{c}\right) \Omega}{F_{c}}+\frac{2 f_{r c} v_{c}}{D}+\frac{g}{v_{c}}\right)$ & $(55)$ \\
\hline $\begin{array}{l}\text { Catalyst and gas velocity distribution } \\
\text { across the riser }\end{array}$ & $\frac{\mathrm{dv}_{\mathrm{g}}}{\mathrm{dx}}=-\left(\frac{\Omega}{\mathrm{F}_{\mathrm{g}}} \frac{\mathrm{dP}_{R S}}{\mathrm{dx}}-\frac{\mathrm{C}_{\mathrm{f}}\left(\mathrm{v}_{\mathrm{c}}-\mathrm{v}_{\mathrm{g}}\right)}{\mathrm{F}_{\mathrm{g}}}+\frac{2 \mathrm{f}_{\mathrm{rg}} \mathrm{v}_{\mathrm{g}}}{\mathrm{D}}+\frac{\mathrm{g}}{\mathrm{v}_{\mathrm{g}}}\right)$ & (56) \\
\hline $\begin{array}{l}\text { Stress modulus of the catalyst (Tsuo and } \\
\text { Gidaspow, 1990) }\end{array}$ & $\mathrm{G}_{\mathrm{c}}=10^{\left(-8.76 \varepsilon_{g}+5.43\right)}$ & $(57)$ \\
\hline $\begin{array}{l}\text { Catalyst temperature at the vaporization } \\
\text { section }\end{array}$ & $\mathrm{T}_{\mathrm{cFS}}=\mathrm{T}_{\mathrm{cCL} 1}-\frac{\mathrm{F}_{\mathrm{lg}}}{\mathrm{F}_{\mathrm{cCL} 1} \mathrm{C}_{p c}}\left[\mathrm{C}_{p l g}\left(\mathrm{~T}_{\mathrm{gFS}}-\mathrm{T}_{\mathrm{lg}}\right)+\frac{\mathrm{F}_{\mathrm{ds}} \mathrm{C}_{p d s}}{\mathrm{~F}_{\mathrm{lg}}}\left(\mathrm{T}_{\mathrm{gFS}}-\mathrm{T}_{\mathrm{ds}}\right)+\Delta H_{v l g}\right]$ & $(58)$ \\
\hline $\begin{array}{l}\text { Gas phase temperature at the vaporization } \\
\text { section }\end{array}$ & $\mathrm{T}_{\mathrm{gFS}}=\frac{\mathrm{B}_{\mathrm{lg}}}{\mathrm{A}_{\mathrm{lg}}-\log \left(\mathrm{P}_{F S} y_{g o F S}\right)}-\mathrm{C}_{\mathrm{lg}}$ & (59) \\
\hline
\end{tabular}




\begin{tabular}{|c|c|c|}
\hline Pressure at the vaporization & $\mathrm{P}_{F S}=\mathrm{P}_{R T}+\Delta \mathrm{P}_{R S}$ & $(60)$ \\
\hline $\begin{array}{l}\text { Weight fraction of feed (gas oil) at the } \\
\text { vaporization section }\end{array}$ & $y_{g o F S}=\frac{\mathrm{F}_{\mathrm{lg}}}{\mathrm{F}_{\mathrm{lg}}+\mathrm{F}_{\mathrm{ds}}}$ & $(61)$ \\
\hline $\begin{array}{l}\text { Velocity of gas phase at the vaporization } \\
\text { section }\end{array}$ & $v_{g F S}=\frac{\mathrm{F}_{\mathrm{lg}}+\mathrm{F}_{\mathrm{ds}}}{\rho_{\mathrm{gFS}}\left(1-\varepsilon_{c C L 1}\right) \Omega_{F S}}$ & $(62)$ \\
\hline $\begin{array}{l}\text { Velocity of entrained catalyst at the } \\
\text { vaporization section }\end{array}$ & $v_{c F S}=\frac{\mathrm{F}_{\mathrm{cCL} 1}}{\rho_{\mathrm{c}} \varepsilon_{c C L 1} \Omega_{F S}}$ & (63) \\
\hline Gas oil density at the vaporization section & $\rho_{g F S}=\frac{\mathrm{P}_{\mathrm{FS}} \mathrm{M}_{\mathrm{wgFS}}}{\mathrm{R}_{g} \mathrm{~T}_{\mathrm{gFS}} \mathrm{Z}_{\mathrm{gFS}}}$ & (64) \\
\hline Catalyst phase velocity & $v_{c R S}^{(0)}=v_{c F S}$ & $(65)$ \\
\hline Gas phase velocity & $v_{g R S}^{(0)}=v_{g F S}$ & $(66)$ \\
\hline Catalyst mass flowrate & $\mathrm{F}_{\mathrm{cRS}}=\mathrm{F}_{\mathrm{cCL} 1}$ & $(67)$ \\
\hline Gas phase mass flowrate & $\mathrm{F}_{\mathrm{gRS}}=\mathrm{F}_{\mathrm{lg}}+\mathrm{F}_{\mathrm{ds}}$ & $(68)$ \\
\hline Heat of vaporization of gas oil & $\Delta H_{v l g}=0.3843 T_{M A B P}+1.0878 * 10^{3} \exp \left(\frac{-M_{w m}}{100}\right)-98.153$ & (69) \\
\hline $\mathrm{Z}$ factor of Heidaryan et al., (2010) & $\mathrm{Z}=\ln \left[\frac{\mathrm{A}_{1}+\mathrm{A}_{3} \ln \left(\mathrm{P}_{\mathrm{pr}}\right)+\frac{\mathrm{A}_{5}}{\mathrm{~T}_{\mathrm{pr}}}+\mathrm{A}_{7}\left(\ln \mathrm{P}_{\mathrm{pr}}\right)^{2}+\frac{\mathrm{A}_{9}}{\mathrm{~T}_{\mathrm{pr}}^{2}}+\frac{\mathrm{A}_{11}}{\mathrm{~T}_{\mathrm{pr}}} \ln \left(\mathrm{P}_{\mathrm{pr}}\right)}{1+\mathrm{A}_{2} \ln \left(\mathrm{P}_{\mathrm{pr}}\right)+\frac{\mathrm{A}_{4}}{\mathrm{~T}_{\mathrm{pr}}}+\mathrm{A}_{6}\left(\ln \mathrm{P}_{\mathrm{pr}}\right)^{2}+\frac{\mathrm{A}_{8}}{\mathrm{~T}_{\mathrm{pr}}^{2}}+\frac{\mathrm{A}_{10}}{\mathrm{~T}_{\mathrm{pr}}} \ln \left(\mathrm{P}_{\mathrm{pr}}\right)}\right]$ & $(70)$ \\
\hline
\end{tabular}




\section{Parameter Estimation Techniques}

220 Parameter estimation is usually carried out for a particular model with the aim of optimising some parameters and in some cases estimating such parameters using experimental data. The optimal estimated parameters are obtained as the best match between the experimental data and the values calculated by the model (Dobre and Marcano, 2007). The use of suitable and accurate models in advance process analysis and optimization is very important. The accuracy of the model for a particular process depend on having the right parameters in use. However, accurate online information of some unknown parameters is difficult to obtain even with accurate models but can be estimated using parameter estimation. It was identified that parameter estimation is not an easy task in the development of process models, weather dynamic or steady state, and that fitting a model to a set of measurement is the challenge (Soroush, 1998).

There are many types of parameter estimation techniques and they are mainly based on the systems used. The parameter estimation by state estimation technique found common use in chemical and biochemical engineering in systems of dynamic models where each model represents an unknown parameter to be estimated (Tatiraju and Soroush, 1997, Soroush, 1997, Soroush, 1998). Another parameter estimation technique is achieved through on-line optimization. This is a case where the estimates are derived from minimization of the sum of squared errors of the optimization problem through comparing the experimental and calculated results within some given range of constraints (Muske and Rawlings, 1995, Robertson et al., 1996). This method has gained acceptance in the parameter estimation of chemical processes (Jarullah et al., 2011) and it is the method used in this work. Another method is the parameter estimation by model inversion (Tatiraju and Soroush, 1998) which comprises a parameter estimate of left inverse of process model concurrently estimating leastsquared errors via on-line measurements (Tatiraju and Soroush, 1998). The method of calorimetric technique for estimating kinetic parameters of process systems is achieved with the use of mass and energy balance models of the systems (Régnier et al., 1996).

246 Parameter estimation for kinetic and compositional values of processes is based on optimization techniques that are either Linear (LN) or non- linear (NLN) regressions. These estimations are readily carried out using computer programs and software (Nowee et al., 2007), which makes complex NLN models much easier to solve. There are many NLN optimization methods such as maximum likelihood estimation (Tjoa and Biegler, 1992) where it seeks a weighted least squares fit to the measurements with an underdetermined 
process model. Other methods includes the Bayesian parameter estimation, which uses the

253

254

255

256

257

258

259

260

261

262

263

264

265

266

267

268

269

270

271

272

273

274

275

276

277

278

279

280

281

282

283

Bayesian regularization back propagation (Ma and Weng, 2009). There is Newton-Raphson method (Souza et al., 2009) which is a robust technique for solving nonlinear problems. There is also the Genetic algorithm and its various types known to be common in academia and the industry due its insightfulness, easy applicability and effectiveness in solving highly nonlinear, mixed integer optimization problems that are typical of complex engineering systems such as the FCC unit (Hassan et al., 2005, Kordabadi and Jahanmiri, 2005, Wang et al., 2005). The Successive Quadratic Programming (SQP) (Tjoa and Biegler, 1992) are readily implementable with the help of computer programming packages and software. It is very much utilized by the gPROMS software (gPROMS, 2013) and it is proved to be very capable (Jarullah et al., 2011).

\subsection{Parameter estimation of kinetic parameters using gPROMS}

Parameter Estimation can be achieved for complex models using the parameter estimation platform of gPROMS software. However, it requires detailed gPROMS process model that captures the system's physical and chemical interactions like the riser model used in this study. The process model representing the system should have parameters that can be tuned to make the model predictions adequately aligned with real data. Such model parameters, particularly in this work, are heat of reactions, frequency factors and activation energies. The more accurate these parameters are, the closer the model's response to reality (gPROMS, 2013). The method used in making these parameters to fit with laboratory or plant/industrial data is called parameter estimation.

gPROMS uses the Maximum Likelihood formulation technique for parameter estimation which estimates parameters in the physical model of the process and the variance model of the measuring instruments. The measuring instrument can be a sensor that is either constant variance for temperature measurement (thermocouple) with an accuracy of $+/-1 \mathrm{~K}$, or constant relative variance for measuring of concentration (composition analyser) with an error of $+/-2 \%$, or both measuring instruments, in which case it is called the heteroscedastic variance, combining both constant variance and constant relative variance (gPROMS, 2013).

The riser process model as shown in Table 1 is a set of differential -algebraic equations (DAEs) with $\xi, \eta$ and $\theta$ as vector parameters to be estimated. In this case,

$\left[k_{o 1}, k_{o 2}, k_{o 3}, k_{o 4}, k_{o 5}\right],\left[E_{1}, E_{2}, E_{3}, E_{4}, E_{5}\right]$ and $\left[\Delta H_{1}, \Delta H_{2}, \Delta H_{3}, \Delta H_{4}, \Delta H_{5}\right]$ for the case of the four-lump model which is used to test the technique employed in this work. 
284 For the case of the six-lump model proposed in this work

$\left[\begin{array}{c}\mathrm{k}_{\mathrm{dz}-\mathrm{gl}}, \mathrm{k}_{\mathrm{dz}-\mathrm{lpg}}, \mathrm{k}_{\mathrm{dz}-\mathrm{dg}}, \mathrm{k}_{\mathrm{gl}-\mathrm{lpg}}, \mathrm{k}_{\mathrm{gl}-\mathrm{dg}}, \mathrm{k}_{\mathrm{gl}-\mathrm{ck}}, \mathrm{k}_{\mathrm{lpg}-\mathrm{dg}}, \mathrm{k}_{\mathrm{lpg}-\mathrm{ck}}, \mathrm{k}_{\mathrm{dg}-\mathrm{ck}} \mathrm{y}_{\mathrm{dg}}, \mathrm{k}_{\mathrm{go}-\mathrm{dz}}, \\ \mathrm{k}_{\mathrm{go}-\mathrm{gl}}, \mathrm{k}_{\mathrm{go}-\mathrm{ck}}, \mathrm{k}_{\mathrm{go}-\mathrm{lpg}}, \mathrm{k}_{\mathrm{go}-\mathrm{dg}}, \mathrm{k}_{\mathrm{dz}-\mathrm{ck}}\end{array}\right]$,

286

$\left[\begin{array}{c}\mathrm{E}_{\mathrm{dz}-\mathrm{gl}}, \mathrm{E}_{\mathrm{dz}-\mathrm{lpg}}, \mathrm{E}_{\mathrm{dz}-\mathrm{dg}}, \mathrm{E}_{\mathrm{gl}-\mathrm{lpg}}, \mathrm{E}_{\mathrm{gl}-\mathrm{dg}}, \mathrm{E}_{\mathrm{gl}-\mathrm{ck}}, \mathrm{E}_{\mathrm{lpg}-\mathrm{dg}}, \mathrm{E}_{\mathrm{lpg}-\mathrm{ck}}, \mathrm{K}_{\mathrm{dg}-\mathrm{ck}}, \mathrm{K}_{\mathrm{go}-\mathrm{dz}} \\ E_{\mathrm{go}-\mathrm{gl}}, \mathrm{E}_{\mathrm{go}-\mathrm{ck}}, \mathrm{E}_{\mathrm{go}-\mathrm{lpg}}, \mathrm{E}_{\mathrm{go}-\mathrm{dg}}, E_{\mathrm{dz}-\mathrm{ck}}\end{array}\right]$ and

$\left[\begin{array}{c}\Delta H_{\mathrm{dz}-\mathrm{gl}}, \Delta H_{\mathrm{dz}-\mathrm{lpg}}, \Delta H_{\mathrm{dz}-\mathrm{dg}}, \Delta H_{\mathrm{gl}-\mathrm{lpg}}, \Delta H_{\mathrm{gl}-\mathrm{dg}}, \Delta H_{\mathrm{gl}-\mathrm{ck}}, \Delta H_{\mathrm{lpg}-\mathrm{dg}}, \Delta H_{\mathrm{lpg}-\mathrm{ck}}, \Delta H_{\mathrm{dg}-\mathrm{ck}}, \\ \Delta H_{\mathrm{go}-\mathrm{dz}}, \Delta H_{\mathrm{go}-\mathrm{gl}}, \Delta H_{\mathrm{go}-\mathrm{ck}}, \Delta H_{\mathrm{go}-\mathrm{lpg}}, \Delta H_{\mathrm{go}-\mathrm{dg}}, \Delta H_{\mathrm{dz}-\mathrm{ck}}\end{array}\right]$.

When solving a Maximum Likelihood Parameter Estimation problem as in this case, gPROMS determines the uncertain physical and variance model parameters values $(\xi, \eta$ and $\theta$ ) which maximise the probability that the mathematical model will predict the measurement values obtained from the experiments. Assuming independent, normally distributed measurement errors $\epsilon_{i j k}$, with zero means and standard deviations, $\sigma_{i j k}$, the estimation is achieved with the use of the following objective function:

$\Phi(\xi, \eta, \theta)=\frac{M}{2} \ln (2 \pi)+\frac{1}{2} \min _{(\xi, \eta, \theta)}\left\{\sum_{i=1}^{M \alpha} \sum_{i=1}^{M \beta_{i}} \sum_{i=1}^{M \gamma_{i j}}\left[\ln \left(\sigma_{i j k}^{2}\right)+\frac{\left(y_{i j k}^{e x p}-y_{i j k}{ }^{c a l}\right)^{2}}{\sigma_{i j k}^{2}}\right]\right\}$

Where $\mathrm{M}$ is total number of measurements taken experimentally and $\xi, \eta \& \theta$ are set of model parameters to be estimated. The acceptable values may be subject to given lower and upper bounds: $\xi^{l} \leq \xi \leq \xi^{u}, \eta^{l} \leq \eta \leq \eta^{u}, \theta^{l} \leq \theta \leq \theta^{u}$.

\subsection{Mathematical formulation for kinetic parameters estimation}

300 The estimation of kinetic parameters using model based technique along with experimental (generated from model and plant) data is carried out in this work. The method involves the use of optimization technique in gPROMS to the minimize sum of squared errors (SSE) between experimental values $y_{i}^{\text {exp }}$ (generated by using a new technique from the model having obtained input and output data from the plant) and calculated values $y_{i}^{\text {cal }}$. This technique has two approaches: first, simulation for converging all the equality constraints and satisfying the inequality constraints and the second, performing the optimization where the objective function is as summarily written:

$\operatorname{Obj}(S S E)=\sum_{M=1}^{M_{t}}\left(y_{i}^{\text {exp }}-y_{i}^{c a l}\right)^{2}$

309 Where $y$ is the mass fraction of lumps and $i$ refers to the various lumps in the riser.

The parameter estimation problem statement can be written as: 
Given

Optimize

So as to minimize The sum of square errors (SSE)

Subject to
311

312 Mathematically;

$313 \min _{\xi_{i 0}, \eta_{i}, \theta_{i}} S S E$

314 s. t.

$f\left(x, z^{\prime}(x), z(x), u(x), v\right)=0 \quad$ (model equations, equality constraints)

$315 \xi^{l} \leq \xi \leq \xi^{u}$ (inequality constraints)

316

$\eta^{l} \leq \eta \leq \eta^{u}$ (inequality constraints)

$\theta^{l} \leq \theta \leq \theta^{u}$

318 Where $f\left(x, z^{\prime}(x), z(x), u(x), v\right)=0$ is model equation, $x$ is height of the riser and the independent variable, $u(x)$ is the decision variable; $\xi$ the frequency factors $k_{o j}$ with $\xi^{u}$ as the upper and $\xi^{l}$ as lower limits; $\eta$ the activation energies $E_{j}$, with $\eta^{u}$ as upper and $\eta^{l}$ as lower limits; $\theta$ as the heat of reaction $\Delta H_{j}$, with $\theta^{u}$ as upper and $\theta^{l}$ as lower limits. $z(x)$ is the differential and algebraic equations while $z^{\prime}(x)$ their derivative. $v$ is the constants parameters.

324 Using industrial data, and FCC unit kinetic and hydrodynamic models, the unknown parameters of the proposed six-lump model in Figure 2 are estimated. The parameters to be estimated are the activation energies, frequency factors and heats of reaction. Here, 45 unknown parameters of the proposed kinetic scheme (15 heats of reaction, $\Delta \mathrm{H}_{\mathrm{j}} ; 15$ frequency factors, $\mathrm{k}_{\mathrm{oj}}$; and 15 activation energies, $\mathrm{E}_{\mathrm{j}}$ ) will be estimated. The frequency factors and activation energies of six lumped models available in the literature are presented in Table 2. The authors did not present the heats of reaction for the various cracking reactions of the six lumps and do not have all the parameters for the cracking reactions LPG to dry gas and coke, and dry gas to coke because the authors assumed the reactions are negligible. In this study, the exiting kinetic data in Table 2 will be used to set guess values, including lower and upper bounds for each parameter on the gPROMS parameter estimation platform to estimate the 45 unknown parameters for the new kinetic scheme proposed in this study. 


\subsubsection{Testing of parameter estimation technique}

338 Figure 4 shows a schematic diagram of the parameter estimation technique used in this work.

339 It describes how input and output data from the plant were used in model simulation to 340 generate online data across the discretised height of the riser which were used to represent

341 experimental data in the gPROMS software for parameter estimation.

342 The feed condition is assumed $100 \%$ gas oil and the riser inlet temperatures of the feed $343(522.9 \mathrm{~K})$ and the catalyst $(904.7 \mathrm{~K})$ from the regenerator. Gas oil input flow rate is $62.5 \mathrm{~kg} / \mathrm{s}$ 344 and that of the catalyst is $400.32 \mathrm{~kg} / \mathrm{s}$, which is a catalyst to oil ratio of 6.41 . Parameter 345 estimation in gPROMS require industrial data of the yields of all lumps of the riser which are 346 used as experiments to estimate the unknown parameters. The available industrial data are the 347 yields of the lumps at the exit of the riser, which are used as experimental data on the 348 parameter estimation platform of gPROMS. The kinetic data in Table 2 are used with the 349 riser model along with the only available industrial riser outputs, which are gas oil; 0.0478, 350 diesel; 0.1857, gasoline; 0.4731, LPG; 0.1518, dry gas; 0.0483 and coke; 0.0891 . The FCC 351 process model is then simulated in gPROMS software to generate yields at discreet points of 352 the riser height which gives more data that are then used on the parameter estimation 353 platform of gPROMS. The newly estimated kinetic parameters are taken back into the riser 354 model to obtain yields that are compared with the ones obtained from the industrial plant as 355 described

in

Figure

4. 
Table 2. Kinetic parameters of six-lumped model in the literature

\begin{tabular}{|c|c|c|c|c|c|c|}
\hline \multirow[t]{2}{*}{ Reaction } & \multicolumn{2}{|c|}{ (Du et al., 2014) } & \multicolumn{2}{|c|}{ (Xiong et al., 2015) } & \multicolumn{2}{|c|}{ (Zhang et al., 2017) } \\
\hline & $\begin{array}{l}\text { Frequency } \\
\text { Factor } \\
\left(\mathbf{k}_{\mathbf{o i}}\right)^{*}\left(\mathbf{s}^{-1}\right)\end{array}$ & $\begin{array}{l}\text { Activation Energy } \\
(\mathrm{kJ} / \mathrm{kmol})\left(\mathrm{E}_{\mathbf{i}}\right)\end{array}$ & $\begin{array}{l}\text { Frequency Factor } \\
\left(\mathbf{k}_{\mathrm{oi}}\right)^{*}\left(\mathrm{~m}^{3} \mathrm{~kg}^{-1} \mathrm{hr}^{-1}\right)\end{array}$ & $\begin{array}{l}\text { Activation } \\
\text { Energy }\left(E_{i}\right) \\
(\mathbf{k J} / \mathbf{m o l})\end{array}$ & $\begin{array}{l}\text { Frequency Factor } \\
\left(\mathbf{k}_{\mathbf{o}}\right)^{*}\left(\mathbf{s}^{-1}\right)\end{array}$ & $\begin{array}{l}\text { Activation } \\
\text { Energy } \\
(\mathbf{k J} / \mathbf{k m o l})\left(\mathbf{E}_{\mathbf{i}}\right)\end{array}$ \\
\hline Gas Oil $\rightarrow$ Diesel & 601.7 & 59.33 & 31328.5 & 47.6 & $6.012 \times 10^{4}$ & 65.14 \\
\hline Gas Oil $\rightarrow$ Gasoline & $2.19 \times 10^{5}$ & 95.00 & 52064.7 & 43.4 & $2.190 \times 10^{5}$ & 90.93 \\
\hline Gas Oil $\rightarrow$ Coke & 28.91 & 177.2 & 574.4 & 30.0 & $0.485 \times 10^{3}$ & 45.10 \\
\hline Gas Oil $\rightarrow$ LPG & 16.96 & 38.05 & 6560.4 & 38.5 & $9.053 \times 10^{6}$ & \begin{tabular}{|l|}
70.53 \\
\end{tabular} \\
\hline Gas Oil $\rightarrow$ Dry Gas & 1869 & 176.44 & 175.6 & 30.2 & $1.870 \times 10^{3}$ & 69.34 \\
\hline Diesel $\rightarrow$ Coke & $2.7 \times 10^{4}$ & 174.4 & 46291.9 & 65.0 & $6.760 \times 10^{3}$ & 61.40 \\
\hline Diesel $\rightarrow$ Gasoline & 240.46 & 57.5 & 14683.7 & 54.1 & $2.400 \times 10^{3}$ & 49.20 \\
\hline Diesel $\rightarrow$ LPG & 46.08 & 141.95 & 40140.4 & 62.9 & $4.680 \times 10^{3}$ & 68.65 \\
\hline Diesel $\rightarrow$ Dry Gas & 1560 & 81.78 & 18604.8 & 66.7 & $1.560 \times 10^{4}$ & 63.23 \\
\hline Gasoline $\rightarrow$ LPG & 40.39 & 74.22 & 494068.4 & 80.5 & $4.039 \times 10^{4}$ & 50.90 \\
\hline Gasoline $\rightarrow$ Dry Gas & 1.6 & 135.34 & 245194.8 & 85.2 & $9.420 \times 10^{3}$ & 36.81 \\
\hline Gasoline $\rightarrow$ Coke & 1.22 & 44.26 & 241931.9 & 77.3 & $0.515 \times 10^{3}$ & 37.23 \\
\hline LPG $\rightarrow$ Dry Gas & 78.98 & 89.27 & $*$ & $*$ & $1.081 \times 10^{4}$ & 65.80 \\
\hline \multicolumn{7}{|l|}{ LPG $\rightarrow$ Coke* } \\
\hline Dry Gas $\rightarrow$ Coke* & & & & & & \\
\hline
\end{tabular}




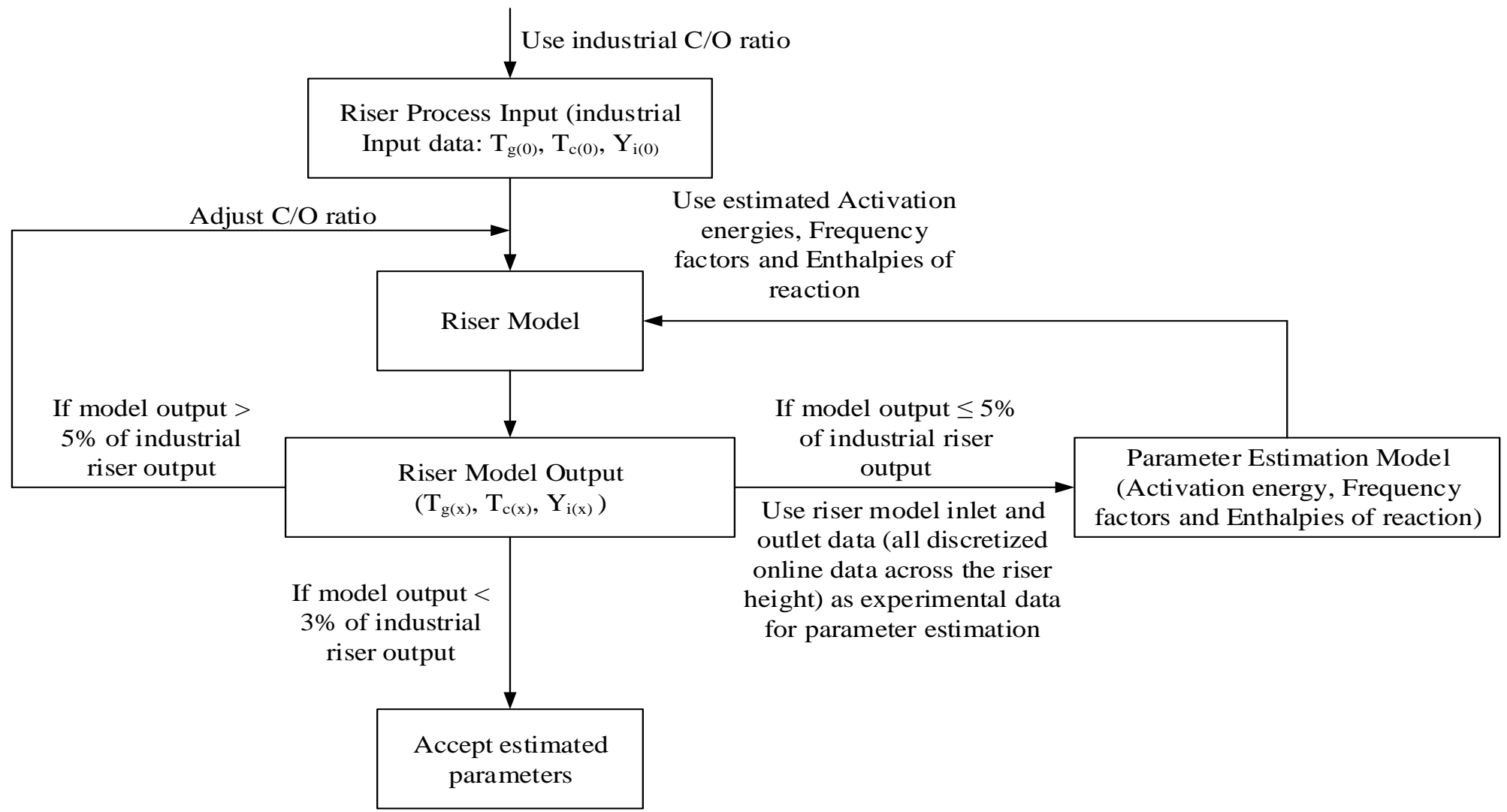

parameters 
361 Since estimated parameters of a process can only be trusted if it is obtained from accurate models of that process, the riser mathematical model used for this parameter estimation was validated to ensure that it is not just accurate enough to simulate the riser, but it is able to estimate those kinetic parameters. Hence, to generate experimental data through simulation with the riser model, a known four-lump kinetic model of the riser (Han and Chung, 2001a, Han and Chung, 2001b) is used. From Figure 4, the procedure requires that the output data from the riser model simulation be compared with the actual plant riser outlet conditions. If the difference between the outputs from the simulation and plant data are less than or equal to $5 \%$, a reasonable limit of error, the values of the lumps and temperatures of the catalyst and gas phases at discrete heights of the riser are taken and used as experimental data on the parameter estimation platform of the gPROMS software. If the outputs from the simulation are more than $5 \%$, the $\mathrm{C} / \mathrm{O}$ ratio is adjusted to obtain riser output in the simulation almost the same as those of the plant. Once this happen, the values of the estimated parameters are deemed 'estimated' and are used in the riser model, which is expected to eventually predict the riser output to be the same as that of the plant. 5\% level of error is accepted because the data generated will be subjected to some optimization during the parameter estimation process, where the level of error is further reduced as the estimated parameters are obtained.

\subsubsection{Testing of parameter estimation technique using four-lumped model}

A four-lumped kinetic model is chosen for testing the parameter estimation strategy because

380 it is most widely used for FCC unit simulation. It also represents the major product classification of the FCC reactant and products, and have all the values of its kinetic parameters validated over the years. Additionally, using kinetic models with more than four lumps means more kinetic parameters to estimate. The less the lumps the fewer the kinetic parameters needed. The four lumped kinetic data in Table 3 are from the literature and have been used by many authors to simulate the FCC riser. In this section, these kinetic data of the four lumped kinetic model are used as guess values with upper and lower bounds, along with the riser mathematical model on the parameter estimation platform of gPROMS.

388 The mass and energy balance, and kinetic model equations used for the four-lump model are presented in Equations (1-14) together with the riser hydrodynamic Equations (44-70) in

390 Table 1. The operational parameters and riser configuration used can be found in the same 391 literature from where the riser model was adopted (Han and Chung, 2001a, Han and Chung, 2001b). The riser conditions (temperatures and compositions) at discrete points along the 
riser height obtained from the procedure in Figure 4 were used as experimental data in the parameter estimation platform of the gPROMS software. The values are presented in Table 4.

Table 3. Kinetic parameters of four-lump model (Han and Chung, 2001b)

\begin{tabular}{llll}
\hline Reaction & $\begin{array}{l}\text { Frequency Factor } \\
\left(\mathrm{k}_{\mathrm{i}}\right)\left(\mathrm{s}^{-1}\right)\end{array}$ & $\begin{array}{l}\text { Activation Energy } \\
(\mathrm{kJ} / \mathrm{kmol})\left(\mathrm{E}_{\mathrm{i}}\right)\end{array}$ & $\begin{array}{l}\text { Heat of Reaction } \\
(\mathrm{kJ} / \mathrm{kmol}) \Delta \mathrm{H}_{\mathrm{i}}\end{array}$ \\
\hline Gas Oil $\rightarrow$ Gasoline & 1457.50 & 57,359 & 195 \\
Gas Oil $\rightarrow$ Gas & 127.59 & 52,754 & 670 \\
Gas Oil $\rightarrow$ Coke & 1.98 & 31,820 & 745 \\
Gasoline $\rightarrow$ Gas & 256.81 & 65,733 & 530 \\
Gasoline $\rightarrow$ Coke & 0.000629 & 66,570 & 690 \\
\hline
\end{tabular}

397

398 Table 4. Riser simulation results of the four-lump kinetic model

\begin{tabular}{|l|l|l|l|l|l|l|}
\hline $\begin{array}{l}\text { Riser } \\
\text { Height } \\
(\mathrm{m})\end{array}$ & $\begin{array}{l}\text { Gas oil } \\
(\text { wt. \% })\end{array}$ & $\begin{array}{l}\text { Gasoline } \\
(\text { wt. \% })\end{array}$ & $\begin{array}{l}\text { Gases } \\
(\text { wt. \%) }\end{array}$ & $\begin{array}{l}\text { Coke } \\
(\text { wt. \% })\end{array}$ & $\begin{array}{l}\text { Temperature } \\
\text { of gas phase } \\
\left(\mathrm{T}_{\mathrm{g}}\right)(\mathrm{K})\end{array}$ & $\begin{array}{l}\text { Temperature of } \\
\text { catalyst phase } \\
\left(\mathrm{T}_{\mathrm{c}}\right)(\mathrm{K})\end{array}$ \\
\hline 0.0 & 1.0000 & 0.0000 & 0.0000 & 0.0000 & 679.0 & 911.6 \\
\hline 5.0 & 0.5945 & 0.2918 & 0.0572 & 0.0295 & 808.5 & 833.7 \\
\hline 10.0 & 0.4598 & 0.3937 & 0.0846 & 0.0313 & 807.6 & 817.6 \\
\hline 15.0 & 0.3806 & 0.4403 & 0.1034 & 0.0352 & 802.2 & 809.1 \\
\hline 20.0 & 0.3333 & 0.4741 & 0.1158 & 0.0348 & 796.8 & 801.3 \\
\hline 25.0 & 0.2989 & 0.4929 & 0.1240 & 0.0409 & 794.6 & 797.8 \\
\hline$* 30.0$ & 0.2750 & 0.5075 & 0.1365 & 0.0426 & 791.1 & 793.7 \\
\hline$* * 30.0$ & 0.2835 & 0.5137 & 0.1332 & 0.0354 & 791.5 & 791.9 \\
\hline$\%$ diff. & 3.00 & 1.21 & 2.48 & 20.34 & 0.05 & 0.23 \\
\hline
\end{tabular}
experimental data

**this row riser exit condition obtained from literature (Han and Chung, 2001a, Han and Chung, 2001b)

403

404 From Table 4, the percentage errors are within some level of acceptability, 5\% and below as described in Figure 4. Percentage difference for the coke lump was much because the value of coke was assumed zero in the feed, which is not always the case. The values of the lumps from the simulation are used as true representation of the online-discretised data along the riser height. They are used as experimental data input in the parameter estimation platform of the gPROMS software and used for the estimation of the four-lump kinetic parameters. The four-lump kinetic parameters estimated are compared in Tables 6,7 and 8 with the existing 
411 four lumped kinetic data from the literature (Han and Chung, 2001a, Han and Chung, 2001b).

412 As can be seen, the ability of the technique in predicting the exiting kinetic parameters is

413 good. Hence, the parameter estimation technique is used to estimate the kinetic parameters of

414 the new six-lumped kinetic model proposed in this work.

415

\subsubsection{Parameter estimation technique using six-lumped model}

417 The overall rate and Arrhenius equations written for the six-lumped model (Equations 21-42)

418 as shown in Table 1, were used with the riser hydrodynamic equations. The kinetic 419 parameters; frequency factors, activation energies and heat of reactions were estimated using 420 guessed values between minimum and maximum of the respective kinetic parameter values in 421 Table 2. In addition, the guess values of the kinetic data used for the cracking of LPG to dry 422 gas and coke, and dry gas to coke on the parameter estimation platform were assumed to be 423 between the minimum and maximum of the kinetic data presented in Table 2. Similarly, 424 simulated results were generated for the six-lump model using the kinetic and hydrodynamic 425 equations following the same parameter estimation technique described in Figure 4. These 426 simulated riser exit compositions are then used as experimental data on the parameter estimation platform of the gPROMS software. The values shown in Table 5 were generated using the real plant configurations and industrial riser input and output conditions (Table A3 of the Appendix) on the PROMS riser simulation.

430 This technique for parameter estimation provides a way to develop new kinetic schemes with just plant data. Once a plant inlet and outlet values (yields and process conditions) are known, along with a robust process model, which describes the process adequately, experimental results can be generated from the process model and be used for parameter estimation. This is a major novel contribution of this work. Another contribution is the development of a new kinetic scheme. Comparing Figures 1 and 2, the cracking reactions of dry gas to coke, and LPG to coke were added to Figure 1 to obtain a new six-lumped kinetic scheme shown in

437 Figure 2. Most authors assumed that those reactions added were usually negligible, because it 438 is usually difficult to measure them. With parameter estimation, it can be seen that they exit. 439 This technique proved to be useful because the parameters estimated were used in the process 440 model to predict the plants data with minimal percentage of errors as shown in Figures 5, 6, 7 441 and 8 . This technique is applicable to both laboratory and plant size processes which is an 442 advantage. 


\section{Results and Discussions}

445 The estimated kinetic parameters and the industrial riser simulation results are presented in 446 this section with the view to demonstrate the accuracy of the technique used in the simulation 447 of the plant where real data was obtained. The simulation also demonstrates the capability of 448 the gPROMS software which is used here for solving the FCC riser complex nonlinear DAEs 449 by validating the results against those of the plant. The estimated parameters for the four450 lump kinetics and six-lump kinetics are also presented.

451 The results of the parameter estimation for the four-lump model denoted with asterisks in 452 Tables 6-8, gives very close estimates as compared with similar values of kinetic data by Han 453 and Chung (2001b) with double asterisks, giving the assurance that the process model can be 454 used for the purpose of parameter estimation. The results are presented in Tables 6-8.

455 Table 5. Riser simulation results of the six-lump kinetic model

\begin{tabular}{|l|l|l|l|l|l|l|l|l|}
\hline $\begin{array}{l}\text { Riser } \\
\text { Height } \\
(\mathrm{m})\end{array}$ & $\begin{array}{l}\text { Gas oil } \\
\text { (wt. \%) }\end{array}$ & $\begin{array}{l}\text { Diesel } \\
\text { (wt. \%) }\end{array}$ & $\begin{array}{l}\text { Gasoline } \\
(\text { wt. \% })\end{array}$ & $\begin{array}{l}\text { LPG } \\
(\text { wt. \% })\end{array}$ & $\begin{array}{l}\text { Dry gas } \\
\text { (wt. \% })\end{array}$ & $\begin{array}{l}\text { Coke } \\
\text { (wt. \%) }\end{array}$ & $\begin{array}{l}\text { Temp. } \\
(\text { Tg) } \\
(\mathrm{K})\end{array}$ & $\begin{array}{l}\text { Temp. } \\
(\mathrm{Tc}) \\
(\mathrm{K})\end{array}$ \\
\hline$* * 0.0$ & 1.0000 & 0.0000 & 0.0000 & 0.0000 & 0.0000 & 0.0000 & 523.0 & 904.7 \\
\hline 5.0 & 0.3479 & 0.2185 & 0.2312 & 0.1073 & 0.0339 & 0.0612 & 706.0 & 775.5 \\
\hline 10.0 & 0.1537 & 0.2652 & 0.3245 & 0.1385 & 0.0434 & 0.0748 & 734.5 & 748.2 \\
\hline 15.0 & 0.0971 & 0.2613 & 0.3686 & 0.1476 & 0.0462 & 0.0792 & 738.4 & 742.2 \\
\hline 20.0 & 0.0724 & 0.2487 & 0.3982 & 0.1516 & 0.0475 & 0.0817 & 738.3 & 740.2 \\
\hline 25.0 & 0.0587 & 0.2349 & 0.4210 & 0.1538 & 0.0482 & 0.0834 & 737.7 & 739.1 \\
\hline 30.0 & 0.0499 & 0.2217 & 0.4398 & 0.1552 & 0.0487 & 0.0847 & 737.0 & 738.2 \\
\hline 35.0 & 0.0438 & 0.2095 & 0.4556 & 0.1562 & 0.0491 & 0.0857 & 736.5 & 737.5 \\
\hline 40.0 & 0.0393 & 0.1983 & 0.4694 & 0.1570 & 0.0494 & 0.0866 & 736.0 & 736.9 \\
\hline 45.0 & 0.0358 & 0.1881 & 0.4815 & 0.1576 & 0.0496 & 0.0873 & 735.5 & 736.4 \\
\hline 47.0 & 0.0346 & 0.1843 & 0.4860 & 0.1578 & 0.0497 & 0.0876 & 735.3 & 736.2 \\
\hline 47.1 & 0.0346 & 0.1841 & 0.4862 & 0.1578 & 0.0497 & 0.0709 & 735.3 & 736.2 \\
\hline$* * 47.1$ & 0.0478 & 0.1857 & 0.4731 & 0.1518 & 0.0483 & 0.0891 & 773.2 & NA \\
\hline$\%$ error & 38.24 & 0.86 & 2.69 & 3.81 & 2.80 & 1.70 & 5.15 & \\
\hline
\end{tabular}


Table 6: Heat of Reaction for four-lump model

\begin{tabular}{llll}
\hline Reaction & $\begin{array}{l}\text { Heat of Reaction** } \\
(\mathrm{kJ} / \mathrm{kmol}) \Delta \mathrm{H}_{\mathrm{i}}\end{array}$ & $\begin{array}{l}\text { Heat of Reaction* } \\
(\mathrm{kJ} / \mathrm{kmol}) \Delta \mathrm{H}_{\mathrm{i}}\end{array}$ & \% Difference \\
\hline Gas Oil $\rightarrow$ Gasoline & 195 & 189 & 3.17 \\
Gas Oil $\rightarrow$ Gas & 670 & 664 & 0.90 \\
Gas Oil $\rightarrow$ Coke & 745 & 739 & 0.81 \\
Gasoline $\rightarrow$ Gas & 530 & 524 & 1.14 \\
Gasoline $\rightarrow$ Coke & 690 & 684 & 0.87 \\
\hline
\end{tabular}

461

*Heat of reaction obtained from the procedure in Figure 4.

$462 * *$ Heat of reaction from literature (Han and Chung, 2001a, Han and Chung, 2001b)

463 Table 7: Frequency factor for four-lump model

\begin{tabular}{llll}
\hline Reaction & $\begin{array}{l}\text { Frequency Factor** } \\
\left(\mathrm{k}_{\mathrm{i}}\right)\left(\mathrm{s}^{-1}\right)\end{array}$ & $\begin{array}{l}\text { Frequency Factor* } \\
\left(\mathrm{k}_{\mathrm{i}}\right)\left(\mathrm{s}^{-1}\right)\end{array}$ & \% Difference \\
\hline Gas Oil $\rightarrow$ Gasoline & 1457.50 & 1468.5 & 0.74 \\
Gas Oil $\rightarrow$ Gas & 127.59 & 134.269 & 4.97 \\
Gas Oil $\rightarrow$ Coke & 1.98 & 1.99911 & 0.95 \\
Gasoline $\rightarrow$ Gas & 256.81 & 253.315 & 1.38 \\
Gasoline $\rightarrow$ Coke & 0.000629 & 0.00052 & 20.96 \\
\hline
\end{tabular}

464

* Frequency Factor obtained from the procedure in Figure 4.

$465 * *$ Frequency Factor from literature (Han and Chung, 2001a, Han and Chung, 2001b)

466

467 Table 8: Activation energy for four-lump model

\begin{tabular}{llll}
\hline Reaction & $\begin{array}{l}\text { Activation Energy** } \\
(\mathrm{kJ} / \mathrm{kmol})\left(\mathrm{E}_{\mathrm{i}}\right)\end{array}$ & $\begin{array}{l}\text { Activation Energy* } \\
(\mathrm{kJ} / \mathrm{kmol})\left(\mathrm{E}_{\mathrm{i}}\right)\end{array}$ & \% Difference \\
\hline Gas Oil $\rightarrow$ Gasoline & 57,359 & 57,348 & 0.01 \\
Gas Oil $\rightarrow$ Gas & 52,754 & 52,765 & 0.02 \\
Gas Oil $\rightarrow$ Coke & 31,820 & 31,809 & 0.03 \\
Gasoline $\rightarrow$ Gas & 65,733 & 65,723 & 0.01 \\
Gasoline $\rightarrow$ Coke & 66,570 & 66,581 & 0.01 \\
\hline
\end{tabular}

$468 *$ Activation Energy obtained from the procedure in Figure 4.

$469 * *$ Activation Energy from literature (Han and Chung, 2001a, Han and Chung, 2001b)

470

471 The differences are 3\% and less, except for the percentage differences between the frequency

472 factors of the reaction of gas oil to gas, which is $4.97 \%$ and gasoline cracking into coke,

473 which has a difference of about $20 \%$ as shown in Table 7 . Although this difference appeared

474 to be very large, it may not be very significant. The reason being that the frequency factor

475 itself is very small, and even though the activation energy and heat of reaction for the

476 reaction may be large, the frequency factor multiplies the exponential term in the Arrhenius

477 equation, which makes the yield of coke very small. It was also found that even when the 
heat of reaction was assumed $1000 \mathrm{~kJ} / \mathrm{kmol}$, the yield of coke is still small because of the value of the frequency factor.

480 Using the new kinetic parameters estimated for the riser simulation with four-lumped model, the riser exit conditions are presented in Table 9. Their percentage errors are all less than 3\%, an acceptable level of marginal error. This low percentage differences in Table 6,7 and 8 shows that the technique used for the parameter estimation as described in Figure 4, is capable of estimating process parameters with very high accuracy. Since the difference of mostly about $3 \%$ and less is seen between the estimated parameters and the literature parameters. This confirms the adequacy of the riser model, the parameter estimation technique proposed in Figure 4 and the new kinetic data for parameter estimation.

Table 9. Riser exit results of the four-lump kinetic model using the new estimated parameters

\begin{tabular}{|l|l|l|l|l|l|l|}
\hline $\begin{array}{l}\text { Riser } \\
\text { Height }(\mathrm{m})\end{array}$ & $\begin{array}{l}\text { Gas oil } \\
(\text { wt. \% })\end{array}$ & $\begin{array}{l}\text { Gasoline } \\
(\text { wt. \% })\end{array}$ & $\begin{array}{l}\text { Gases } \\
(\text { wt. \% })\end{array}$ & $\begin{array}{l}\text { Coke } \\
(\text { wt. \% })\end{array}$ & $\begin{array}{l}\text { Temp. ( } \\
(\mathrm{K})\end{array}$ & $\begin{array}{l}\text { Temp. }\left(\mathrm{T}_{\mathrm{c}}\right) \\
(\mathrm{K})\end{array}$ \\
\hline$* 30$ & 0.2835 & 0.5137 & 0.1332 & 0.0354 & 791.5 & 791.9 \\
\hline$* * 30$ & 0.2803 & 0.5134 & 0.1366 & 0.0354 & 791.7 & 792.1 \\
\hline$\%$ diff. & 1.14 & 0.06 & 2.49 & 0.0000 & 0.03 & 0.03 \\
\hline
\end{tabular}

Table 10 shows the new six-lump estimated parameters. Being the first of such six-lumped 493 kinetic model that considered the cracking of LPG and dry gas to coke, as well as the cracking of dry gas to coke. In Table 10, the frequency factors, activation energies and heats of reaction of the cracking reactions of LPG to dry gas and coke, and dry gas to coke, for the six lumped kinetic model are presented. These data were not available in the open literature, which is a contribution of this work. Overall, a new six lumped kinetic data (Table 10) is presented in this work. For the purpose of validation, the newly estimated kinetic data in Table 10 is simulated with the riser process model, and exit values were compared with the exit conditions of industrial riser.

501 The process model was run on the gPROMS simulation platform using the new six-lump kinetic parameters with the new kinetic scheme in Figure 2. At $\mathrm{C} / \mathrm{O}$ ratio of 6.405 , the feed (gas oil at $62.5 \mathrm{~kg} / \mathrm{s}$ ) meets the regenerated catalyst $(400.32 \mathrm{~kg} / \mathrm{s}$ ) at the feed vaporization 
505 The cracking reaction starts at gas oil inlet temperature of $523.0 \mathrm{~K}$ and catalyst inlet temperature of $904 \mathrm{~K}$. The profiles of the products are shown in Figure 4.

507 The amount of the gas oil at the exit of the riser is 0.0346 ( $\mathrm{kg}$ lump/ $\mathrm{kg}$ feed) which is $3.46 \%$

508 of gas oil left unreacted. It also means that, about $96.54 \%$ of gas oil reacted and above $80 \%$

509 of the reacted fraction was consumed in the first $12 \mathrm{~m}$ of the riser. In some risers, most of the

510 conversion takes place in the first $10 \mathrm{~m}$. This may not be the same for some short risers.

511 Some of the risers are $30 \mathrm{~m}$ high and others are less (Han and Chung, 2001b, John et al.,

512 2017b, John et al., 2017a). Here, the riser is $47.1 \mathrm{~m}$ high. The amount of diesel at the exit of

513 the riser is 0.1842 ( $\mathrm{kg}$ lump/kg feed) which is $18.42 \%$ of total products formed. The product

514 gasoline formed is 0.4863 ( $\mathrm{kg} \mathrm{lump} / \mathrm{kg}$ feed), that is $48.63 \%$ of total products formed. Other

515 products formed are LPG; 0.1577 ( $\mathrm{kg}$ lump/kg feed) which is $15.77 \%$ of products formed,

516 dry gas; 0.0497 ( $\mathrm{kg}$ lump/kg feed) which is $4.97 \%$ of total products formed, and coke; 0.0876

517 (kg lump/kg feed), 8.76\% of total product formed in the riser. These outputs from the riser

518 are compared with the riser plant data in Table 11. The diesel and gasoline profiles increases

519 from 0 ( $\mathrm{kg}$ lump/ $\mathrm{kg}$ feed) at the inlet of the riser to its maximum yield of $0.4863(\mathrm{~kg}$ lump/ $\mathrm{kg}$

520 feed) at the riser exit for gasoline and a maximum of 0.2660 ( $\mathrm{kg}$ lump/ $\mathrm{kg}$ feed) for diesel in

521 the first $11 \mathrm{~m}$. However, the mass fraction of diesel increases initially and then decreases

522 gradually to 0.1858 ( $\mathrm{kg}$ lump $/ \mathrm{kg}$ feed) at the end of the riser. This fraction of diesel decreased

523 after $11 \mathrm{~m}$ due to a secondary reaction, which is common for intermediates in a series -

524 parallel reactions. The endothermic heat was sufficient to convert the diesel into gasoline and

525 other intermediates. The other products of the riser; LPG, dry gas and coke all started from

526 zero weight fraction as well and rose to their maximum at approximately $11 \mathrm{~m}$ height, but

527 essentially levels out at the exit of the riser. The profiles of the lumps in the riser qualitatively

528 compare favorably with the profiles of riser products in the literature (John et al., 2017a, John

529 et al., 2017b, Du et al., 2014, Han and Chung, 2001b). 
537 Table 10. Kinetic parameters of six-lump model estimated

\begin{tabular}{llll}
\hline Reaction & $\begin{array}{l}\text { Frequency Factor } \\
\left(\mathbf{k}_{\mathbf{i}}\right)\left(\mathbf{s}^{-\mathbf{1}}\right)\end{array}$ & $\begin{array}{l}\text { Activation Energy } \\
(\mathbf{k J} / \mathbf{k m o l})\left(\mathbf{E}_{\mathbf{i}}\right)\end{array}$ & $\begin{array}{l}\text { Heat of Reaction } \\
(\mathbf{k J} / \mathbf{k m o l}) \Delta_{\mathbf{i}}\end{array}$ \\
\hline Gas Oil $\rightarrow$ Diesel & 7957.29 & $53,927.7$ & 190.709 \\
Gas Oil $\rightarrow$ Gasoline & $14,433.4$ & $57,186.6$ & 128.45 \\
Gas Oil $\rightarrow$ Coke & 40.253 & $32,433.6$ & 458.345 \\
Gas Oil $\rightarrow$ LPG & 2337.1 & $51,308.6$ & 209.192 \\
Gas Oil $\rightarrow$ Dry Gas & 449.917 & $48,620.4$ & 44.543 \\
Diesel $\rightarrow$ Coke & 75.282 & $61,159.4$ & 305.925 \\
Diesel $\rightarrow$ Gasoline & 197.933 & $48,114.5$ & 513.568 \\
Diesel $\rightarrow$ LPG & 3.506 & $67,792.9$ & 90.894 \\
Diesel $\rightarrow$ Dry Gas & 3.395 & $64,266.6$ & 204.381 \\
Gasoline $\rightarrow$ LPG & 2.189 & $56,194.4$ & 225.082 \\
Gasoline $\rightarrow$ Dry Gas & 1.658 & $63,319.1$ & 19.667 \\
Gasoline $\rightarrow$ Coke & 2.031 & $61,785.1$ & 117.212 \\
LPG $\rightarrow$ Dry Gas & 3.411 & $55,513.0$ & 17.618 \\
LPG $\rightarrow$ Coke & 0.601 & $52,548.2$ & 11.839 \\
Dry Gas $\rightarrow$ Coke & 2.196 & $53,046.0$ & 52.863 \\
\hline & & & \\
\hline
\end{tabular}




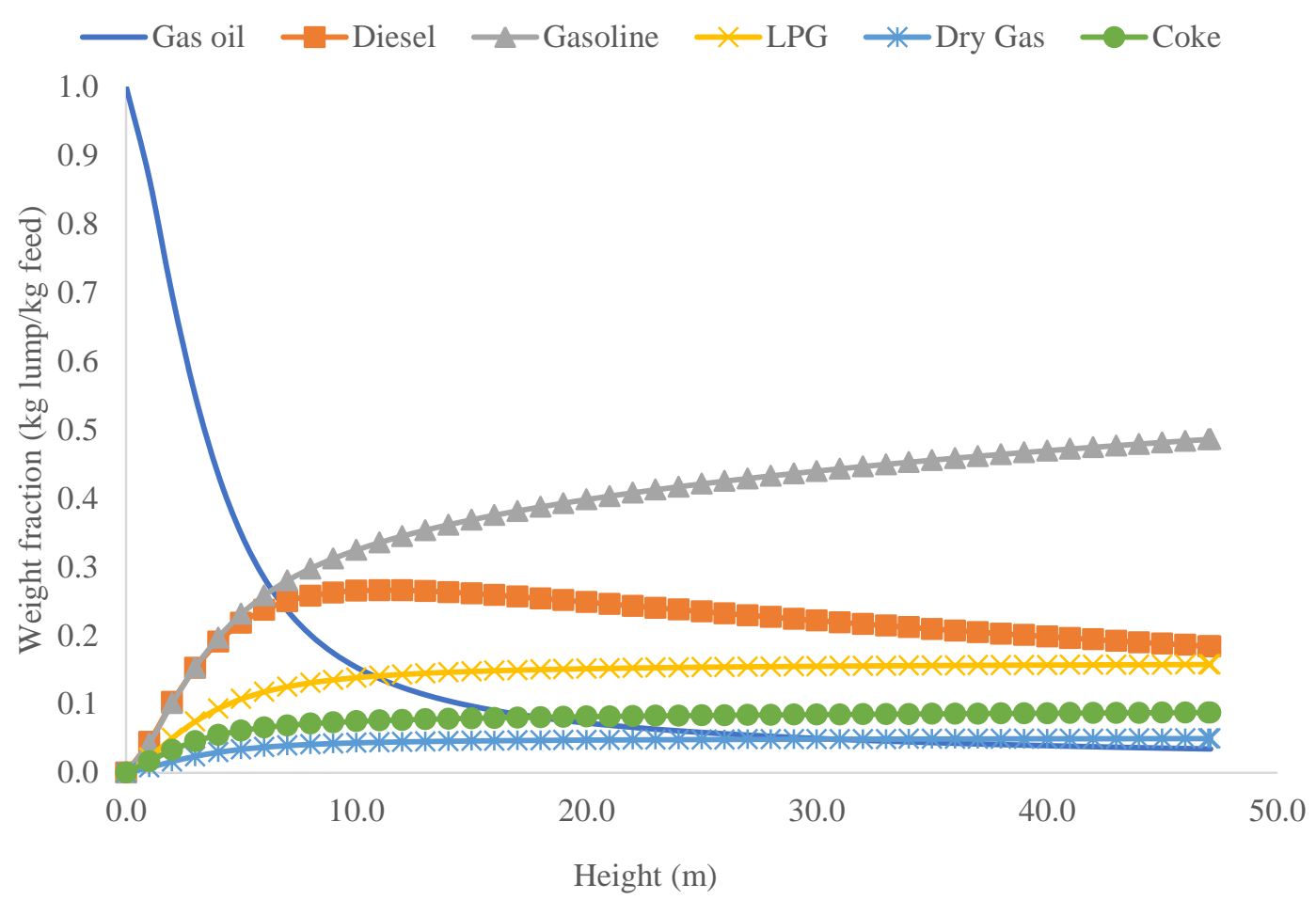

541 Figure 5. Profile of gas oil cracking in the riser

543 Figure 5 shows the temperature profiles of the gas and catalyst phases as a function of riser 544 height. The temperature of the catalyst-phase starts from about $933 \mathrm{~K}$ in the feed vaporization 545 section and decreases for the first $11 \mathrm{~m}$ from $904.7 \mathrm{~K}$ at the entrance of the riser and then 546 essentially levels out to $736.2 \mathrm{~K}$ at the riser exit.

547 The temperature profile of the gas phase starts from $478.15 \mathrm{~K}$, which is also the temperature 548 of the gas oil coming into the vaporization section. This temperature was quickly raised by 549 the incoming hot regenerated catalyst to about $522.9 \mathrm{~K}$ as can be seen at the riser inlet in 550 Figure 5. This gas phase temperature rises from $522.9 \mathrm{~K}$ to a peak $738.5 \mathrm{~K}$ in the first $17 \mathrm{~m}$ of 551 the riser and levels out in the remaining portion of the riser. The difference in both 552 temperature profiles represents the endothermic reaction in the riser with a temperature 553 difference of $382.2{ }^{\circ} \mathrm{C}$ at the riser inlet to $0.95{ }^{\circ} \mathrm{C}$ at the exit. This difference aid the 554 completion of the cracking reaction and represents the heat of removal shown in Figure 9, 555 which is accounted for in this work with the help of the estimated heat of reactions obtained 556 and shown in Table 10. The temperature profiles obtained in this work are qualitatively 557 similar to those obtained in many literatures (Han and Chung, 2001b, Du et al., 2014, John et 558 al., 2017b, John et al., 2017a). 
559 To determine the accuracy and validate the capability of this gPROMS model, refinery 560 operational data are used to compare with the results of this simulation work. The results are 561 shown in Table 11.

562

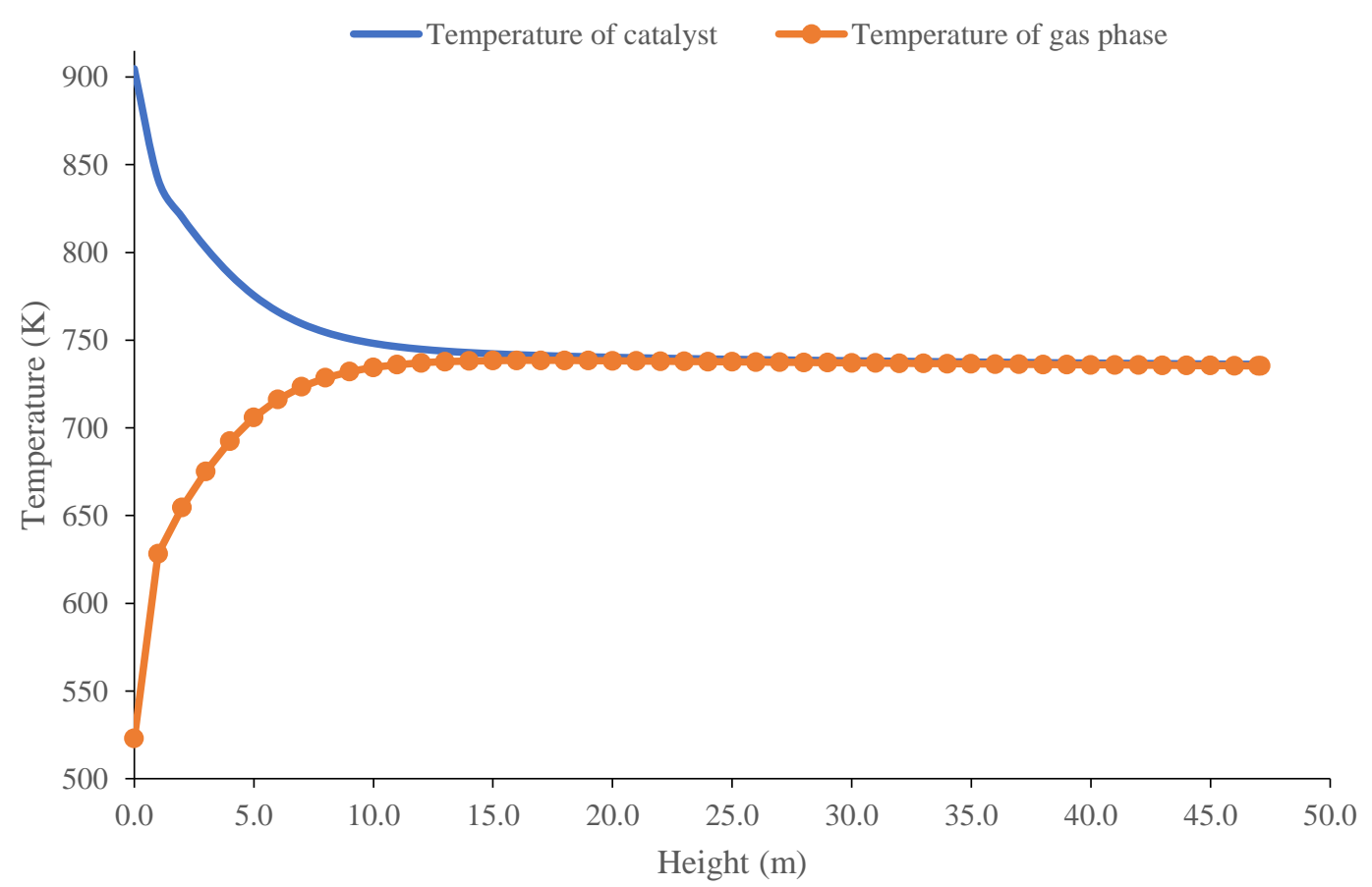

563

564 Figure 6. Temperature profiles across the riser.

565

566 Table 11: Riser simulation results compared with plant data

\begin{tabular}{lllll}
\hline Parameter & Input & Riser output & Plant data & \% difference \\
\hline Gas oil Temperature (K) & 478.15 & 735.3 & 773.2 & 5.15 \\
Catalyst Temperature (K) & 905 & 736.2 & & \\
Gas oil Mass flowrate (kg/s) & 62.5 & 62.5 & 62.5 & \\
Catalyst Mass flowrate (kg/s) & 400.32 & 400.32 & 400.32 & \\
Mass fraction of Gas oil (wt. \%) & 1.0 & 0.0346 & 0.0478 & 38.15 \\
Mass fraction of Diesel (wt. \%) & 0.0 & 0.1842 & 0.1857 & 0.81 \\
Mass fraction of Gasoline (wt. \%) & 0.0 & 0.4863 & 0.4731 & 2.71 \\
Mass fraction of LPG (wt. \%) & 0.0 & 0.1577 & 0.1518 & 3.74 \\
Mass fraction of Dry gas (wt. \%) & 0.0 & 0.0497 & 0.0483 & 2.28 \\
Mass fraction of Coke (wt. \%) & 0.0 & 0.0876 & 0.0891 & 1.71 \\
\hline
\end{tabular}


567 The temperature of the catalyst is $905 \mathrm{~K}$ at the inlet of the riser and gradually decreased to $568736.2 \mathrm{~K}$ at the riser exit due to endothermic cracking reactions. The decrease in the catalyst temperature increased the temperature of the gas phase from $478.2 \mathrm{~K}$ at the riser inlet to $735.3 \mathrm{~K}$ at the exit. For the gas phase temperature at the riser exit, there is a $5.15 \%$ difference between the riser exit temperature in this simulation $735.30 \mathrm{~K}$ and that of the plant $(773.20$

$572 \mathrm{~K})$. The $5.15 \%$ difference can be acceptable considering that the yield of products is not only 573 dependent on reaction temperature but as well as the hydrodynamics of the riser, C/O ratio, catalyst type, nature of feed and many other operational variables. This temperature difference between plant data and the simulation result is evident in the increased conversion found in this simulation, showing that more heat of the endothermic reaction was utilized. The feed conversion in this work is higher than that obtained in the plant, with a $38.15 \%$ increase on the fraction of feed converted. This increase is far above the $3 \%$ difference required for the estimated parameter to be accepted. However, most of the values of the sixlump are less than 3\% and so the results are acceptable. The most valuable products are the diesel and gasoline and the parameter estimated was able to predict the plant values with about an average of over $98 \%$ accuracy. The percentage difference compared with the plant data for the diesel is $0.81 \%$ and for gasoline, it is $2.71 \%$. The percentage difference between the value for the lighter products LPG and dry gas are $3.74 \%$ and $2.28 \%$ respectively, which are also acceptable values within margin of difference. The major products are diesel and gasoline and are within acceptable margin of error. Although the difference between the predicted values and plant data for gas oil value at the exit of the riser is large, it can be corrected by optimizing the $\mathrm{C} / \mathrm{O}$ ratio and other operational variables of the unit. The percentage differences in Table 11 shows that the estimated kinetic parameters are accurate and can be used for the simulation of the riser of FCC unit.

591 Figure 7 shows the velocity profiles of the gas and catalyst phase along the riser height. The 592 velocity profile of catalyst rose from $18.8 \mathrm{~m} / \mathrm{s}$ at entrance of the riser to $44.94 \mathrm{~m} / \mathrm{s}$ at the exit. 593 The velocity profile of the gas phase rose sharply from $8.79 \mathrm{~m} / \mathrm{s}$ to $21.25 \mathrm{~m} / \mathrm{s}$ in the first $1 \mathrm{~m}$ 594 of the riser, and eventually rose to $44.81 \mathrm{~m} / \mathrm{s}$ at the exit of the riser. This gives a slip velocity 595 of $10.01 \mathrm{~m} / \mathrm{s}$ at the entrance to $0.13 \mathrm{~m} / \mathrm{s}$ at the exit, making an average slip velocity of 0.29 $\mathrm{m} / \mathrm{s}$ across the riser. The slip velocity is very close to $0.25 \mathrm{~m} / \mathrm{s}$ presented in the literature (Han and Chung, 2001b). 


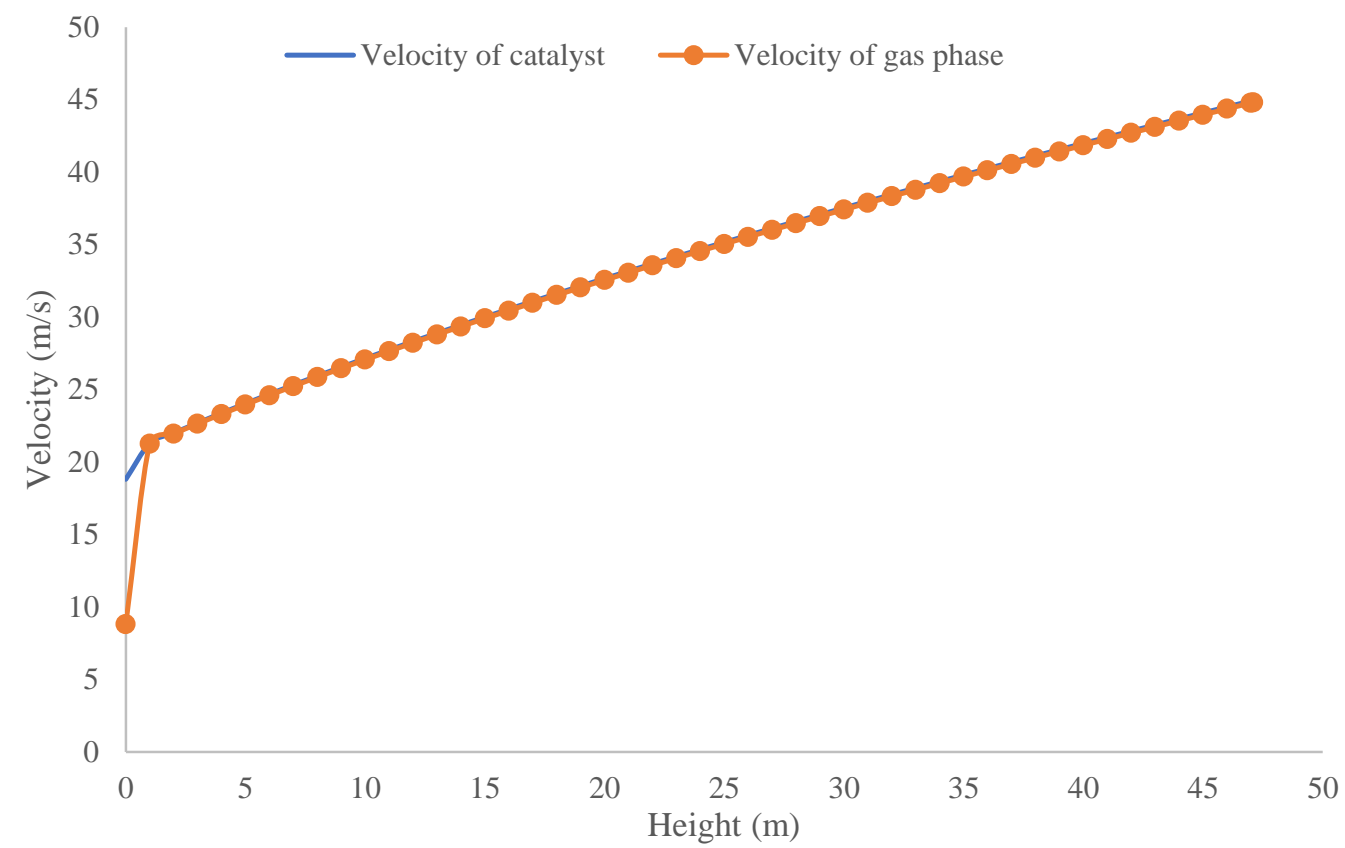

599 Figure 7. Velocity profiles across the riser

600 Figure 8 shows that the profile of pressure in the riser decreases from $340.5 \mathrm{kPa}$ at the 601 entrance to $296.1 \mathrm{kPa}$ at the exit. The pressure drop is thus $44.9 \mathrm{kPa}$ and could be as high as $602163 \mathrm{kPa}$ industrial risers (Chang et al., 2012).

603

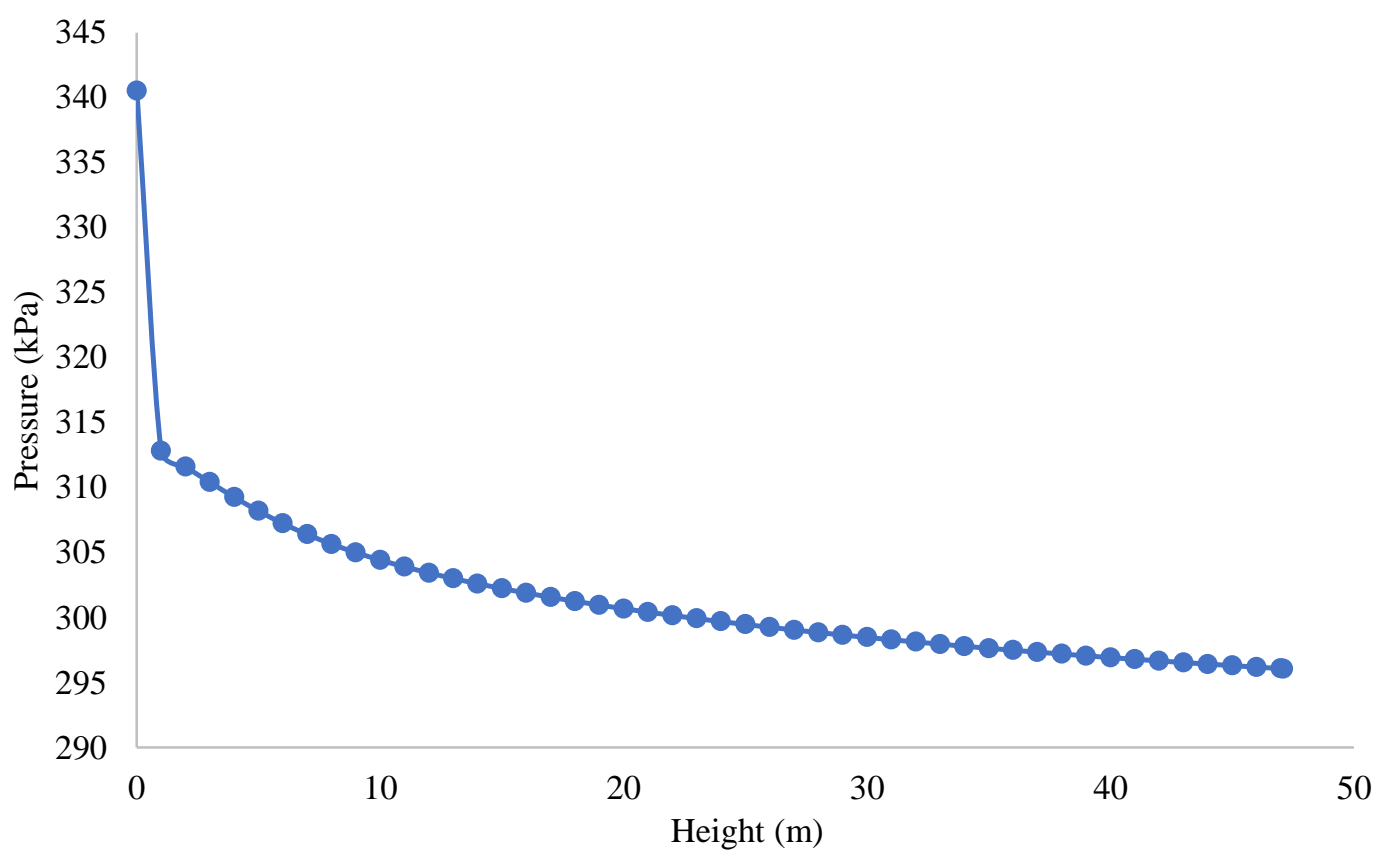

604

605 Figure 8. Pressure profile along the riser 
606 Although the model simulation predicts the pressure drop, it is only limited to the riser and 607 the effect of the regenerator pressure was not considered which could be a reason for the 608 variation of pressure drop in this study compared with other predicted pressure drops (Chang 609 et al., 2012, Han and Chung, 2001b). Another reason could be that, since the pressure of the 610 riser in the plant is measured at the end of the disengaging section, which is not captured in 611 this simulation, more pressure drop is expected to be recorded in the plant. In addition, 612 product streams are many times used for quenching of the cracking reactions at the riser end, 613 which affects the pressure in the disengaging section. Though, the pressure drop is 614 quantitatively different from the pressure drop of the plant $(30 \mathrm{kPa})$, the profile is 615 qualitatively similar to the ones in the literature (Han and Chung, 2001b).

616 The heat released with the catalyst from the regenerator reimburses the heat requirements for 617 the endothermic cracking reactions in the riser which causes the unit to operate, overall, 618 under conditions of thermal balance. The same heat coming with the regenerated catalyst is 619 useful for heating and evaporating the feed; gas oil, as it moves pneumatically upward into 620 the riser. This process brings about heat removal due to the endothermic heats of the cracking reactions (Arbel et al., 1995) which strongly affects the overall heat balance in the FCC unit.

622 This heat removal is measured as a function of the enthalpies of the various cracking lumps.

623 It is possible to measure the heat removal as shown in Figure 9 from the estimated heats of 624 reactions in Table 10.

625 At the entrance of the riser, much heat is removed because of the fast cracking reaction and 626 vaporization. Also, most of the products are formed in the first few meters of the riser. After 627 about $10 \mathrm{~m}$ of the riser, heat removal is almost constant for the remaining parts of the riser.

628 The simulation in this work was carried out at $\mathrm{C} / \mathrm{O}$ ratio of 6.405 which means the gas oil 629 mass flowrate at $62.5 \mathrm{~kg} / \mathrm{s}$ and the regenerated catalyst mass flowrate at $400.32 \mathrm{~kg} / \mathrm{s}$. The C/O 630 ratio was changed from 6.405 to 5.405 and compared with the plant data, though, the plant 631 data was obtained at $\mathrm{C} / \mathrm{O}$ ratio of 6.405 . In the absence of the plant data at the varied $\mathrm{C} / \mathrm{O}$ 632 ratio of 5.405, its outputs are compared with the plant data at 6.405 . The results are shown in 633 Table 12.

634 In varying the $\mathrm{C} / \mathrm{O}$ ratios, only the mass flowrate of the gas oil was varied while the mass 635 flowrate of catalyst was kept constant. This is because mass flowrate of gas oil can be 636 directly manipulated unlike the mass flow rate of catalyst which depends on many other 637 variables including fresh catalyst addition. 


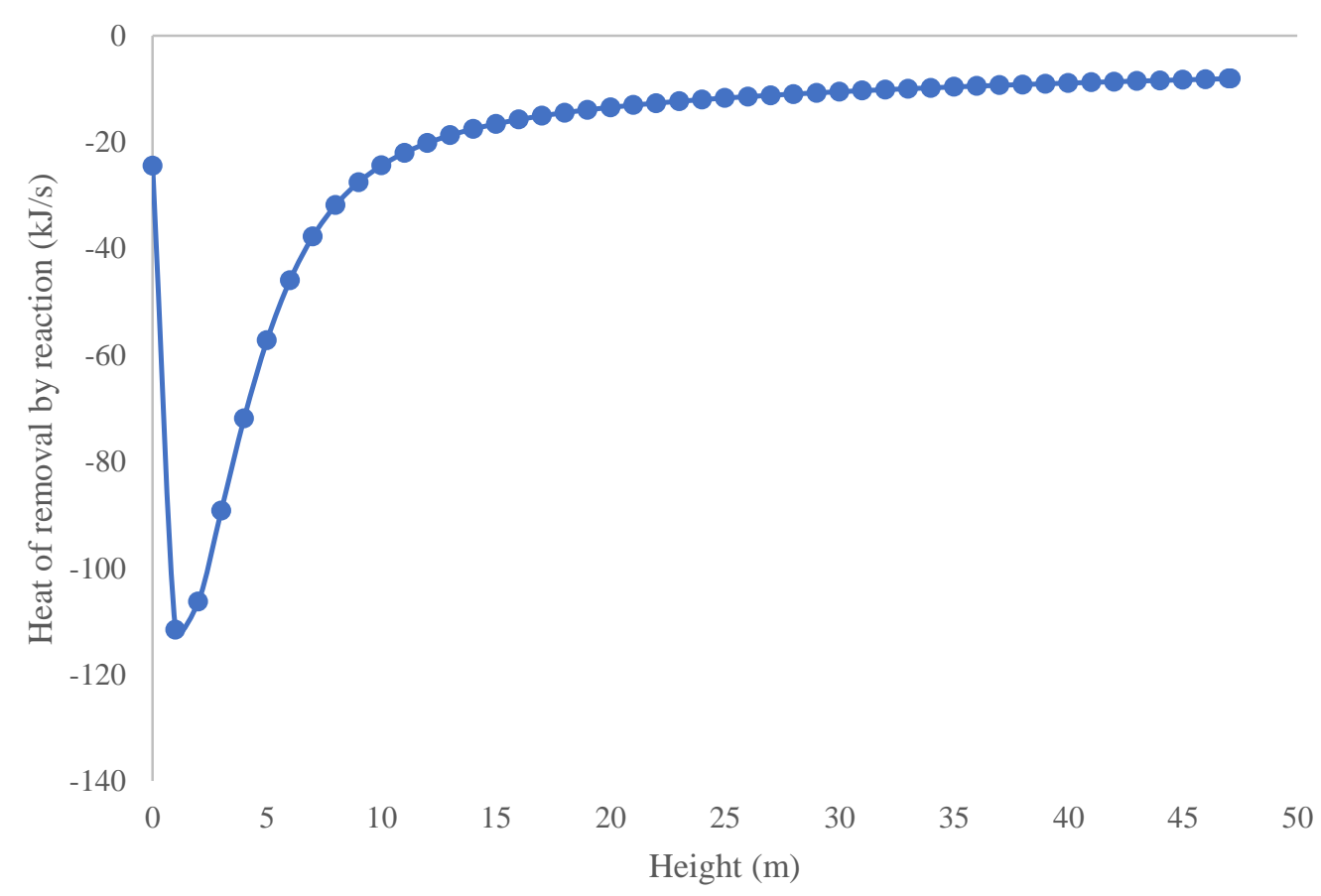

639

640 Figure 9. Profile of heat removal along the riser

641 At $74.06 \mathrm{~kg} / \mathrm{s}$, a C/O ratio of 5.406, it is a $15.61 \%$ increase on mass flowrate of gas oil. This 642 lower $\mathrm{C} / \mathrm{O}$ ratio compared to 6.405 of the plant brought about $11.15 \%$ increase in the 643 converted fraction of gas oil from 0.0478 to $0.0538 \mathrm{~kg}$-lump/kg-feed. This increased 644 conversion leads to $17.80 \%$ increase in diesel yield from 0.1857 to $0.2259 \mathrm{~kg}$-lump $/ \mathrm{kg}$-feed. 645 However, there is a significant decrease in the yield of gasoline from 0.4731 to $0.4305 \mathrm{~kg}$ 646 lump/kg-feed $(9.90 \%$ decrease $)$. This is because the riser exit temperature for this simulation 647 being $712.7 \mathrm{~K}, 8.49 \%$ lower than the riser exit temperature of the plant $(773.2 \mathrm{~K})$, and favors 648 the cracking of heavier products like diesel compared with gasoline. This difference also 649 caused considerable percentage decrease in the lighter products and coke.

650 At $62.5 \mathrm{~kg} / \mathrm{s}$, the same mass flowrate of gas oil of the plant, the $\mathrm{C} / \mathrm{O}$ ratio is 6.406 . The 651 converted fraction of gas oil is $0.0478 \mathrm{~kg}$-lump/kg-feed for the plant and $0.0346 \mathrm{~kg}-\mathrm{lump} / \mathrm{kg}$ 652 feed for this simulation. This is equivalent to $38.15 \%$ increase on the conversion of gas oil. 653 This increase has caused a $0.81 \%$ increase of $0.1857 \mathrm{~kg}$-lump/kg-feed of diesel for plant to $6540.1842 \mathrm{~kg}$-lump/kg-feed for this simulation at $\mathrm{C} / \mathrm{O}$ ratio of 6.406 . Likewise, the increase 655 caused a $2.71 \%$ increase of $0.4731 \mathrm{~kg}$-lump/kg-feed of gasoline for the plant, to $0.4863 \mathrm{~kg}$ 656 lump/kg-feed for this simulation at C/O ratio of 6.406. This shows that at C/O ratio of 6.406, 
657 the percentage conversion of the gas oil is $38.15 \%$, which is higher than $11.15 \%$ at $\mathrm{C} / \mathrm{O}$ ratio of 5.406 .

659 The two simulation outputs shown in Table 12 are obtained at C/O ratios of 5.405 and 6.405.

660 Comparing their percentage differences with the plant data, there is a decrease of $8.49 \%$ in 661 gas oil temperature at $\mathrm{C} / \mathrm{O}=5.405$, while, there is a decrease of $5.15 \%$ in gas oil temperature 662 at $\mathrm{C} / \mathrm{O}=6.405$. This shows that increase in $\mathrm{C} / \mathrm{O}$ ratio could increase the gas phase 663 temperature, which eventually favours conversion as seen; a 38.15\% increase in conversion 664 at $\mathrm{C} / \mathrm{O}=6.405$ as against $11.15 \%$ increase at $\mathrm{C} / \mathrm{O}=5.405$. However, increase in $\mathrm{C} / \mathrm{O}$ ratio 665 from 5.406 to 6.406 gives a lower diesel yield $(17.8 \%$ at $\mathrm{C} / \mathrm{O}=5.404$ and $0.81 \%$ at $\mathrm{C} / \mathrm{O}=$ 666 6.404) and higher gasoline yield (a decrease of $9.90 \%$ at $\mathrm{C} / \mathrm{O}=5.404$ and $2.71 \%$ at $\mathrm{C} / \mathrm{O}=$ 667 6.404). This means that higher $\mathrm{C} / \mathrm{O}$ ratios may favor increased gas oil conversion but results 668 in decrease yield of diesel.

669

670 Table 12: Compare riser output results for different $\mathrm{C} / \mathrm{O}$ ratio

\begin{tabular}{|l|l|l|l|l|l|}
\hline Riser Parameter & Plant & $\begin{array}{l}\text { Simulation } \\
\text { Output @ } \\
\text { C/O } \\
\text { Ciff. } \\
5.405\end{array}$ & $\begin{array}{l}\text { C/O } \\
=5.405\end{array}$ & $\begin{array}{l}\text { Simulation } \\
\text { Output @ } \\
\text { C/O } \\
6.405\end{array}$ & $\begin{array}{l}\text { Diff. } \\
\text { C/O } \\
=6.405\end{array}$ \\
\hline Catalyst-to-oil ratio (C/O) & 6.405 & 5.405 & & $6.405^{*}$ & \\
\hline Catalyst Mass flowrate (kg/s) & 400.32 & 400.32 & 0.0 & 400.32 & 0.0 \\
\hline Gas oil Mass flowrate (kg/s) & 62.50 & 74.06 & 15.61 & 62.50 & 0 \\
\hline Gas oil Temperature (K) & 773.2 & 712.7 & -8.49 & 735.3 & -5.15 \\
\hline Catalyst Temperature (K) & N/A & 713.6 & N/A & 736.2 & N/A \\
\hline Mass fraction of Gas oil (wt. \%) & 0.0478 & 0.0538 & 11.15 & 0.0346 & 38.15 \\
\hline Mass fraction of Diesel (wt. \%) & 0.1857 & 0.2259 & 17.80 & 0.1842 & 0.81 \\
\hline Mass fraction of Gasoline (wt. \%) & 0.4731 & 0.4305 & -9.90 & 0.4863 & 2.71 \\
\hline Mass fraction of LPG (wt. \%) & 0.1518 & 0.1550 & 2.06 & 0.1577 & 3.74 \\
\hline Mass fraction of Dry gas (wt. \%) & 0.0483 & 0.0488 & 1.02 & 0.0497 & 2.28 \\
\hline Mass fraction of Coke (wt. \%) & 0.0891 & 0.0861 & -3.48 & 0.0876 & 1.71 \\
\hline
\end{tabular}


672 Therefore, the plant needs to be operated at lower $\mathrm{C} / \mathrm{O}$ ratio for increased diesel yield, while

673

674

675

676

677

678

679

680

681

682

683

684

685

686

687

688

689

690

691

692

693

694

695

696

697

698 increased $\mathrm{C} / \mathrm{O}$ ratio favors the yield of gasoline. In addition, if the production objective is to produce gasoline, then higher $\mathrm{C} / \mathrm{O}$ ratio is appropriate. Increased $\mathrm{C} / \mathrm{O}$ ratio also increase the temperature of the riser which favors secondary reactions. This is one of the reasons for gasoline yield to increase with increase in $\mathrm{C} / \mathrm{O}$ ratio. This variation of the $\mathrm{C} / \mathrm{O}$ ratio, a major influence on the FCC unit, follows a typical FCC riser behaviour (León-Becerril et al., 2004, John et al., 2017b).

\section{Conclusions}

In this work, a steady state detailed industrial FCC riser process model is simulated to carry out parameter estimation of a new six-lump kinetic model of gas oil cracking. The new sixlump model was implemented on gPROMS software to crack gas oil into diesel, gasoline, LPG, dry gas and coke. The following conclusions can be made:

- A new kinetics scheme has been developed which includes the cracking of LPG to coke and dry gas, as well as the cracking of dry gas into coke.

- New activation energies, frequency factors and heat of reactions for a new six-lump kinetic model were estimated.

- The estimated parameters predicts the major industrial riser fractions; diesel is 0.1842 $\mathrm{kg}$-lump $/ \mathrm{kg}$-feed with a $0.81 \%$ error while gasoline is $0.4863 \mathrm{~kg}$-lump $/ \mathrm{kg}$-feed with a $2.71 \%$ error compared with the plant data.

- With the help of the new kinetic parameters, the heat of cracking reaction was estimated for the six lumped model for the first time.

- The estimated parameters can be used to simulate any type of FCC riser with a sixlump model since $\mathrm{C} / \mathrm{O}$ ratios were varied and the results showed agreement with the typical riser profiles.

\section{Notation}

A

$A_{p t c}$

C

$C_{p_{g}}$
Surface area, $\mathrm{m}^{2}$

Effective interface heat transfer area per unit volume, $\mathrm{m}^{2} / \mathrm{m}^{3}$

Mole concentration, $\mathrm{kg}$ mole $/ \mathrm{m}^{3}$

Gas heat capacity, kJ/kg K 

Aromatics-to-Naphthenes ratio in liquid feedstock Average sphericity of catalyst particles
Total mass interchange rate between the emulsion and bubble phases, $1 / \mathrm{s}$
Temperature, $\mathrm{K}$
Reduced temperature
superficial velocity, $\mathrm{m} / \mathrm{s}$
Volume, $\mathrm{m}^{3}$ 
Weight fraction

Gas compressibility factor or $\mathrm{Z}$ factor

\section{Greek}

$\Omega$

$\rho$

$\emptyset$

$\varepsilon$

$\alpha$

$\alpha_{C}^{*}$

$\mu_{\mathrm{g}}$

$\Phi$

$M \alpha$

$M \beta_{i}$

$M \gamma_{i j}$

$\sigma_{i j k}^{2}$

$\hat{y}_{i j k}$

$y_{i j k}$

\section{Subcript}

$\mathrm{cc}$

CL1

ck

$\mathrm{dg}$

Ds

$\mathrm{dz}$

FS

g
Cross-sectional area (units)

Density, $\mathrm{kg} / \mathrm{m}^{3}$

Catalyst deactivation function

Voidage

Catalyst deactivation coefficient

exponent for representing $\alpha$

viscosity (units)

Maximum likelihood objective function

Number of experiments performed

Number of variables measured in the $i$ th experiment

Number of measurements of the $j$ th variable in the $i$ th experiment

Variance of the kth measurement of variable $\mathrm{j}$ in experiment $i$.

This is determined by the measured variable's variance model kth measured value of variable $\mathrm{j}$ in experiment $i$ kth (model-)predicted value of variable $j$ in experiment $i$

Coke on catalyst

Cyclone 1

Coke

Dry gas

Disperse steam

Diesel

Feed vaporization section

Acceleration $\mathrm{m} / \mathrm{s}^{2}$ 
gl

go

gs

j

MABP

MeABP

pc

$\mathrm{pr}$

Rs

RT gasoline

Gas oil

gas

Reaction path

Molal average boiling temperature, $\mathrm{K}$

Mean average boiling temperature, $\mathrm{K}$

pseudo-critical

pseudo-reduced

Riser

Disengager-stripping section

699

700

701

702

703

704

705 
706 Appendix A

707 Table A.1 and Equations A.1 - A.24 are correlations of physical and transport parameters 708 adopted from the literature (Han and Chung, 2001a, Han and Chung, 2001b).

709 Table A.1: Distillation Coefficients

\begin{tabular}{lll}
\hline Volume \% distilled & $\mathrm{a}$ & $\mathrm{b}$ \\
\hline 10 & 0.5277 & 1.0900 \\
30 & 0.7429 & 1.0425 \\
50 & 0.8920 & 1.0176 \\
70 & 0.8705 & 1.0226 \\
90 & 0.9490 & 1.0110 \\
\hline
\end{tabular}

710

711 Heat capacity of gas, $\mathrm{C}_{\mathrm{pg}}$, is

$712 \quad C_{p g}=\beta_{1}+\beta_{2} T_{g}+\beta_{3} T_{g}^{2}$

713 Where $\beta_{1}, \beta_{2}, \beta_{3}$ and $\beta_{4}$ catalyst decay constant given as

$714 \quad \beta_{1}=-1.492343+0.124432 \mathrm{~K}_{\mathrm{f}}+\beta_{4}\left(1.23519-\frac{1.04025}{\mathrm{~S}_{\mathrm{g}}}\right)$

$715 \quad \beta_{2}=\left(-7.53624 \times 10^{-4}\right)\left[2.9247-\left(1.5524-0.05543 \mathrm{~K}_{\mathrm{f}}\right) \mathrm{K}_{\mathrm{f}}+\beta_{4}\left(6.0283-\frac{5.0694}{\mathrm{~S}_{\mathrm{g}}}\right)\right]$

716

$717 \quad \beta_{3}=\left(1.356523 \times 10^{-6}\right)\left(1.6946+0.0884 \beta_{4}\right)$

$718 \quad \beta_{4}=\left[\left(\frac{12.8}{\mathrm{Kf}}-1\right)\left(1-\frac{10}{\mathrm{Kf}}\right)\left(\mathrm{S}_{\mathrm{g}}-0.885\right)\left(\mathrm{S}_{\mathrm{g}}-0.7\right)\left(10^{4}\right)\right]^{2}$ For $10<\mathrm{Kf}<12.8$

719 Else $\beta_{4}=0$ for all other cases

720 Kf is the Watson characterization factor written as

$721 \quad \mathrm{Kf}=\frac{\left(1.8 \mathrm{~T}_{\mathrm{MeABP}}\right)^{\frac{1}{3}}}{\mathrm{~S}_{\mathrm{g}}}$ 
724 The molecular weight $\mathrm{M}_{\mathrm{wg}}$ of the gas can be calculated using

$$
\begin{aligned}
& \mathrm{M}_{\mathrm{wg}}=42.965 {\left[\operatorname { e x p } \left(2.097 \times 10^{-4} \mathrm{~T}_{\text {MeABP }}-7.787 \mathrm{~S}_{\mathrm{g}}+2.085\right.\right.} \\
&\left.\left.\times 10^{-3} \mathrm{~T}_{\text {MeABP }} \mathrm{S}_{\mathrm{g}}\right)\right]\left(\mathrm{T}_{\text {MeABP }}^{1.26007} \mathrm{~S}_{\mathrm{g}}{ }^{4.98308}\right)
\end{aligned}
$$

725

$726 \mathrm{~T}_{\mathrm{MeABP}}=\mathrm{T}_{\mathrm{VABP}}-0.5556 \exp \left[-0.9440-0.0087\left(1.8 \mathrm{~T}_{\mathrm{VABP}}-491.67\right)^{0.6667}+\right.$

$7272.9972(\mathrm{Sl})^{0.3333}$

728 Where $\mathrm{T}_{\mathrm{VABP}}$, the volume average boiling temperature and $\mathrm{Sl}$ is slope given as

729

$\mathrm{Sl}=0.0125\left(\mathrm{~T}_{90 \mathrm{ASTM}}-\mathrm{T}_{10 \mathrm{ASTM}}\right)$

$730 \quad \mathrm{~T}_{\text {VABP }}=0.2\left(\mathrm{~T}_{10 \text { ASTM }}+\mathrm{T}_{30 \text { ASTM }}+\mathrm{T}_{50 \text { ASTM }}+\mathrm{T}_{\text {70ASTM }}+\mathrm{T}_{90 A S T M}\right)$

731 The ASTM D86 distillation temperatures are calculated using

$732 \quad \mathrm{~T}_{10 \text { ASTM }}=\mathrm{a}_{10}^{-\frac{1}{\mathrm{~b}_{10}}}\left(\mathrm{~T}_{10 \mathrm{TBP}}\right)^{\frac{1}{\mathrm{~b}_{10}}}$

$733 \quad \mathrm{~T}_{30 \text { ASTM }}=\mathrm{a}_{30}^{-\frac{1}{\mathrm{~b}_{30}}}\left(\mathrm{~T}_{30 \mathrm{TBP}}\right)^{\frac{1}{\mathrm{~b}_{30}}}$

$734 \quad \mathrm{~T}_{50 \mathrm{ASTM}}=\mathrm{a}_{50}^{-\frac{1}{\mathrm{~b}_{50}}}\left(\mathrm{~T}_{50 \mathrm{TBP}}\right)^{\frac{1}{\mathrm{~b}_{50}}}$

$735 \mathrm{~T}_{70 \mathrm{ASTM}}=\mathrm{a}_{70}^{-\frac{1}{\mathrm{~b}_{70}}}\left(\mathrm{~T}_{70 \mathrm{TBP}}\right)^{\frac{1}{\mathrm{~b}_{70}}}$

$736 \mathrm{~T}_{90 \mathrm{ASTM}}=\mathrm{a}_{90}^{-\frac{1}{\mathrm{~b}_{90}}}\left(\mathrm{~T}_{90 \mathrm{TBP}}\right)^{\frac{1}{\mathrm{~b}_{90}}}$

737 Where $a_{i}$ and $b_{i}$ are distillation coefficients (Table A.1) and $T_{\text {iTBP }}$ is the initial TBP 738 distillation temperature.

739 Interface heat transfer coefficient between the catalyst and gas phases, $\mathrm{h}_{\mathrm{p}}$,

$740 \quad \mathrm{~h}_{\mathrm{p}}=0.03 \frac{\mathrm{K}_{\mathrm{g}}}{\mathrm{d}_{\mathrm{c}}^{\frac{2}{3}}}\left[\frac{\left|\left(\mathrm{v}_{\mathrm{g}}-\mathrm{v}_{\mathrm{c}}\right)\right| \rho_{\mathrm{g}} \varepsilon_{\mathrm{g}}}{\mu_{\mathrm{g}}}\right]^{\frac{1}{3}}$

741 Thermal conductivity of hydrocarbons

742

$$
\mathrm{K}_{\mathrm{g}}=1 \times 10^{-6}\left(1.9469-0.374 \mathrm{M}_{\mathrm{wm}}+1.4815 \times 10^{-3} \mathrm{M}_{\mathrm{wm}}^{2}+0.1028 \mathrm{~T}_{\mathrm{g}}\right)
$$


$744 \mathrm{M}_{\mathrm{WM}}$ is the mean molecular weight of the combined catalyst and gas

$745 \quad \mathrm{M}_{\mathrm{WM}}=\frac{1}{\left(\frac{\mathrm{ygo}}{\mathrm{M}_{\mathrm{wgo}}}+\frac{\mathrm{ygl}}{\mathrm{M}_{\mathrm{wgl}}}+\frac{\mathrm{ydz}}{\mathrm{M}_{\mathrm{wdz}}}+\frac{\mathrm{ylpg}}{\mathrm{M}_{\mathrm{wlpg}}}+\frac{\mathrm{ydg}}{\mathrm{M}_{\mathrm{wdg}}}+\frac{\mathrm{yck}}{\mathrm{M}_{\mathrm{ck}}}\right)}$

$746 \quad \mathrm{M}_{\mathrm{wgo}}=\mathrm{M}_{\mathrm{wg}}$

$747 \quad \mathrm{M}_{\mathrm{wdg}}=0.0146 \mathrm{M}_{\mathrm{wH}}+0.4161 \mathrm{M}_{\mathrm{wC}}+0.5693 \mathrm{M}_{\mathrm{wC}_{2}}$

748

$\mathrm{M}_{\mathrm{lpg}}=0.3441 \mathrm{M}_{\mathrm{wC}_{3}}+0.6559 \mathrm{M}_{\mathrm{wC}}$

749 The viscosity of the gas

750

$\mu_{\mathrm{g}}=3.515 \times 10^{-8} \mu_{\mathrm{pr}} \frac{\sqrt{\mathrm{M}_{\mathrm{WM}} \mathrm{P}_{\mathrm{pc}}^{\frac{2}{3}}}}{\mathrm{~T}_{\mathrm{pc}}^{\frac{1}{6}}}$

751

$\mu_{\mathrm{pr}}=0.435 \exp \left[\left(1.3316-\mathrm{T}_{\mathrm{pr}}^{0.6921}\right) \mathrm{P}_{\mathrm{pr}}\right] \mathrm{T}_{\mathrm{pr}}+0.0155$

$$
\mathrm{T}_{\mathrm{pc}}=17.1419\left[\exp \left(-9.3145 \times 10^{-4} \mathrm{~T}_{\mathrm{MeABP}}-0.5444 \mathrm{~S}_{\mathrm{g}}+6.4791 \times 10^{-4} \mathrm{~T}_{\mathrm{MeABP}} \mathrm{S}_{\mathrm{g}}\right)\right]
$$

$$
\times \mathrm{T}_{\mathrm{MeAB}}^{-0.4844} \mathrm{~S}_{\mathrm{g}}^{4.0846}
$$

753

$$
\mathrm{P}_{\mathrm{pc}}=4.6352 \times 10^{6}\left[\exp \left(-8.505 \times 10^{-3} \mathrm{~T}_{\mathrm{MeABP}}-4.8014 \mathrm{~S}_{\mathrm{g}}+5.749 \times 10^{-3} \mathrm{~T}_{\mathrm{MeABP}} \mathrm{S}_{\mathrm{g}}\right)\right]
$$

$$
\times \mathrm{T}_{\mathrm{MeAB}}^{-0.4844} \mathrm{~S}_{\mathrm{g}}^{4.0846}
$$

755 Table A.2: Tuned coefficients for $0.2 \leq P_{p r} \leq 3$ (Heidaryan et al., 2010)

\begin{tabular}{|l|l|}
\hline Coefficient & $\begin{array}{l}\text { Tuned } \\
\text { Coefficient }\end{array}$ \\
\hline A1 & 2.827793 \\
\hline A2 & -0.4688191 \\
\hline A3 & -1.262288 \\
\hline A4 & -1.536524 \\
\hline A5 & -4.535045 \\
\hline A6 & 0.06895104 \\
\hline A7 & 0.1903869 \\
\hline A8 & 0.6200089 \\
\hline A9 & 1.838479 \\
\hline A10 & 0.4052367 \\
\hline A11 & 1.073574 \\
\hline
\end{tabular}

757 Table A.3 summarizes the variables, feed and catalyst characteristic and other parameters used in this simulation. Most of the parameters were obtained from the FCC unit in Sudan and the literature (Han and Chung, 2001b, Ahari et al., 2008, John et al., 2017b). 
760 Table A.3: Specifications of constant parameters and differential variables at $x=0$.

\begin{tabular}{|c|c|}
\hline Variable & Value \\
\hline Riser Height, $x(\mathrm{~m})$ & 47.1 \\
\hline $\mathrm{T}_{\mathrm{g}}(0)$ (Temperature of gas oil, $\mathrm{K}$ ) & 478.15 \\
\hline $\mathrm{T}_{\mathrm{c}}(0)$ (Temperature of gas catalyst, $\mathrm{K}$ ) & 905 \\
\hline D Riser Diameter (m) & 1.36 \\
\hline $\mathrm{F}_{\mathrm{c}}($ Catalyst mass flowrate, $\mathrm{kg} / \mathrm{s})$ & 400.32 \\
\hline $\mathrm{F}_{\mathrm{g}}($ Gas oil mass flowrate, $\mathrm{kg} / \mathrm{s})$ & 62.5 \\
\hline $\mathrm{y}_{\mathrm{go}}(0)$ Mass fraction of gas oil ( $\mathrm{kg} \mathrm{lump} / \mathrm{kg}$ feed) & 1.0 \\
\hline $\mathrm{y}_{\mathrm{gl}}(0)$ Mass fraction of gasoline ( $\mathrm{kg}$ lump/kg feed) & 0.0 \\
\hline $\mathrm{y}_{\mathrm{dz}}(0)$ Mass fraction of diesel ( $\mathrm{kg}$ lump/kg feed) & 0.0 \\
\hline $\mathrm{y}_{\mathrm{dg}}(0)$ Mass fraction of dry gas ( $\mathrm{kg}$ lump/kg feed) & 0.0 \\
\hline $\mathrm{y}_{\text {lpg }}(0)$ Mass fraction of LPG ( $\mathrm{kg}$ lump/kg feed) & 0.0 \\
\hline $\mathrm{y}_{\mathrm{ck}}(0)$ Mass fraction of coke ( $\mathrm{kg}$ lump/kg feed) & 0.0 \\
\hline $\mathrm{M}_{\text {wgo }}$ Molecular weight gas oil $(\mathrm{kg} / \mathrm{k} \mathrm{mol})$ & 371 \\
\hline $\mathrm{M}_{\mathrm{wgl}}$ Molecular weight gasoline (kg/k mol) & 106.7 \\
\hline $\mathrm{M}_{\mathrm{wdz}}$ Molecular weight diesel $(\mathrm{kg} / \mathrm{k} \mathrm{mol})$ & 178.6 \\
\hline $\mathrm{M}_{\mathrm{wck}}$ Molecular weight coke $(\mathrm{kg} / \mathrm{k} \mathrm{mol})$ & 14.4 \\
\hline $\mathrm{d}_{\mathrm{c}}$ (Average particle diameter, $\mathrm{m}$ ) & 0.000065 \\
\hline$S_{c}$ (Average sphericity of catalyst particles) & 0.72 \\
\hline $\mathrm{S}_{\mathrm{g}}$ (Specific gravity) & 0.9019 \\
\hline $\mathrm{C}_{\mathrm{ckCL} 1}$ (Coke on catalyst, $\mathrm{kg}$ coke/kg catalyst) & 0.001 \\
\hline$\alpha_{\mathrm{c} 0}\left(\right.$ pre-exponential factor of $\left.\alpha_{c}\right)$ & $1.1 \mathrm{e}-5$ \\
\hline$\alpha_{\mathrm{c}^{*}}($ Catalyst deactivation coefficient) & 0.1177 \\
\hline $\mathrm{C}_{\mathrm{pc}}($ Heat capacity of catalyst, $\mathrm{kJ} / \mathrm{kg} \mathrm{K})$ & 1.15 \\
\hline$\rho_{c}\left(\right.$ Density of catalyst, $\left.\mathrm{kg} / \mathrm{m}^{3}\right)$ & 720 \\
\hline $\mathrm{R}_{\mathrm{AN}}$ (Aromatics/Naphthenes in liquid feedstock) & 2.1 \\
\hline $\mathrm{T}_{10 \text { твP }}$ TBP distilled 10 volume $\%,{ }^{\circ} \mathrm{C}$ & 368 \\
\hline $\mathrm{T}_{\text {30твP }}, \mathrm{TBP}$ distilled 30 volume $\%,{ }^{\circ} \mathrm{C}$ & 453 \\
\hline $\mathrm{T}_{\text {50твP }}, \mathrm{TBP}$ distilled 50 volume $\%,{ }^{\circ} \mathrm{C}$ & 472 \\
\hline $\mathrm{T}_{70 \text { твр }}$ TBP distilled 70 volume $\%,{ }^{\circ} \mathrm{C}$ & 528 \\
\hline $\mathrm{T}_{90 \text { TвP }}$ TBP distilled 90 volume $\%,{ }^{\circ} \mathrm{C}$ & 644 \\
\hline
\end{tabular}




\begin{tabular}{ll}
\hline $\mathrm{E}_{\mathrm{c}}$ Catalyst Activation Energy (kJ/kg mol) & 49,000 \\
$\mathrm{M}_{\mathrm{wH}_{2}}$ Molecular weights of hydrogen $(\mathrm{kg} / \mathrm{k} \mathrm{mol})$ & 2 \\
$\mathrm{M}_{\mathrm{wC}}$ Molecular weights of methane $(\mathrm{kg} / \mathrm{k} \mathrm{mol})$ & 16 \\
$\mathrm{M}_{\mathrm{wC}_{2}}$ Molecular weights of ethane $(\mathrm{kg} / \mathrm{k} \mathrm{mol})$ & 30 \\
$\mathrm{M}_{\mathrm{wC}}$ Molecular weights of propane $(\mathrm{kg} / \mathrm{k} \mathrm{mol})$ & 44 \\
$\mathrm{M}_{\mathrm{wC}}$ Molecular weights of butane $(\mathrm{kg} / \mathrm{k} \mathrm{mol})$ & 58 \\
$\mathrm{~g}$, acceleration due to gravity $\left(\mathrm{m} / \mathrm{s}^{2}\right)$ & 9.8 \\
$\mathrm{R}$, ideal gas constant $(\mathrm{kPa} \mathrm{m} 3 / \mathrm{kg}$ mole K) & 8.3143
\end{tabular}

\section{References}

763

764

765

766

767

768

769

770

771

772

773

774

775

776

777

778

779

780

781

782

783

784

785

786

787

788

789

790

791

792

793

794

AHARI, J. S., FARSHI, A. \& FORSAT, K. 2008. A Mathematical Modeling of the Riser Reactor in Industrial FCC Unit. Petroleum \& Coal, 50, 15-24.

ALI, H., ROHANI, S. \& CORRIOU, J. P. 1997. Modelling and Control of a Riser Type Fluid Catalytic Cracking (FCC) Unit. Chemical Engineering Research and Design, 75, 401412.

ARANDES, J. M., AZKOITI, M. J., BILBAO, J. \& DE LASA, H. I. 2000. Modelling FCC Units under Steady and Unsteady State Conditions. The Canadian Journal of Chemical Engineering, 78.

ARBEL, A., HUANG, Z., RINARD, I. H. \& SHINNAR, R. 1995. Dynamic and Control of Fluidized Catalytic Crackers. 1. Modeling of the Current Generation of FCC's. Ind. Eng. Chem. Res., 34, 1228-1243.

BALDESSAR, F. \& NEGRÃO, C. O. R. 2005. SIMULATION OF FLUID CATALYTIC CRACKING RISERS - A SIX LUMP MODEL. 18th International Congress of Mechanical Engineering Ouro Preto, $M G$.

BOLLAS, G. M., VASALOS, I. A., LAPPAS, A. A., IATRIDIS, D. K. \& TSIONI, G. K. 2004. Bulk Molecular Characterization Approach for the Simulation of FCC Feedstocks. Ind. Eng. Chem. Res., 43, 3270-3281.

CHANG, J., MENG, F., WANG, L., ZHANG, K., CHEN, H. \& YANG, Y. 2012. CFD investigation of hydrodynamics, heat transfer and cracking reaction in a heavy oil riser with bottom airlift loop mixer. Chemical Engineering Science, 78, 128-143.

DOBRE, T. G. \& MARCANO, J. G. S. 2007. Chemical Engineering Modelling Simulation and Similitude, Germany, WILEY-VCH Verlag GmbH \& Co. KGaA, Weinheim.

DU, Y. P., YANG, Q., ZHAO, H. \& YANG, C. H. 2014. An integrated methodology for the modeling of Fluid Catalytic Cracking (FCC) riser reactor. Applied Petrochemical Research, 4, 423-433.

DUPAIN, X., GAMAS, E. D., MADON, R., KELKAR, C. P., MAKKEE, M. \& MOULIJN, J. A. 2003. Aromatic gas oil cracking under realistic FCC conditions in a microriser reactoris. Fuel, 82, 1559-1569.

GAO, H., WANG, G., XU, C. \& GAO, J. 2014. Eight-Lump Kinetic Modeling of Vacuum Residue Catalytic Cracking in an Independent Fluid Bed Reactor. Energy \& Fuels, $28,6554-6562$.

GPROMS 2013. Model Validation Guide. Process Systems Enterprise Limited. 
GUPTA, R. K., KUMAR, V. \& SRIVASTAVA, V. K. 2007. A new generic approach for the modeling of fluid catalytic cracking (FCC) riser reactor. Chemical Engineering Science, 62, 4510-4528.

HAGELBERG, P., EILOS, I., HILTUNEN, J., LIPIÄINEN, K., NIEMI, V. M., AITTAMAA, J. \& KRAUSE, A. O. I. 2002. Kinetics of catalytic cracking with short contact times. Applied Catalysis A: General, 223, 73-84.

HAN, I.-S. \& CHUNG, C.-B. 2001a. Dynamic modeling and simulation of a fluidized catalytic cracking process. Part I: Process modeling. Chemical Engineering Science, 56, 1951-1971.

HAN, I.-S. \& CHUNG, C.-B. 2001b. Dynamic modeling and simulation of a fluidized catalytic cracking process. Part II: Property estimation and simulation. Chemical Engineering Science, 56, 1973-1990.

HASSAN, R., COHANIM, B., DE WECK, O. \& VENTER, G. 2005. A Comparison of Particle Swarm Optimization and the Genetic Algorithm. In: HASSAN, R. (ed.) 46th AIAA/ASME/ASCE/AHS/ASC Structures, Structural Dynamics \& Materials Conference. Austin, Texas: American Institute of Aeronautics and Astronautics.

HEIDARYAN, E., MOGHADASI, J. \& RAHIMI, M. 2010. New correlations to predict natural gas viscosity and compressibility factor. Journal of Petroleum Science and Engineering, 73, 67-72.

HEYDARI, M., ALEEBRAHIM, H. \& DABIR, B. 2010. Study of Seven-Lump Kinetic Model in the Fluid Catalytic Cracking Unit. American Journal of Applied Sciences, 7, 71-76.

JACOB, S. M., GROSS, B., VOLTZ, S. E. \& WEEKMAN, V. W. 1976. A lumping and reaction scheme for catalytic cracking. AIChE Journal, 22, 701-713.

JARULLAH, A. T., AWAD, N. A. \& MUJTABA, I. M. 2017. Optimal design and operation of an industrial fluidized catalytic cracking reactor. Fuel, 206, 657-674.

JARULLAH, A. T., MUJTABA, I. M. \& WOOD, A. S. 2011. Kinetic parameter estimation and simulation of trickle-bed reactor for hydrodesulfurization of crude oil. Chemical Engineering Science, 66, 859-871.

JOHN, Y. M., PATEL, R. \& MUJTABA, I. M. 2017a. Maximization of Gasoline in an Industrial Fluidized Catalytic Cracking Unit. Energy \& Fuels, 31, 5645-5661.

JOHN, Y. M., PATEL, R. \& MUJTABA, I. M. 2017b. Modelling and simulation of an industrial riser in fluid catalytic cracking process. Computers \& Chemical Engineering.

JOHN, Y. M., PATEL, R. \& MUJTABA, I. M. 2017c. Optimization of Fluidized Catalytic Cracking Unit Regenerator to Minimize CO2 Emissions. CHEMICAL ENGINEERING TRANSACTIONS; The Italian Association of Chemical Engineering, 57.

JORGE ANCHEYTA JUAREZ, F. L.-I., ENRIQUE AQUILAR-RODRIQUEZ 1999. 5Lump Kinetic Model for Gas Oil Cracking. Applied Catalysis A: General, 177, $227-$ 235.

KORDABADI, H. \& JAHANMIRI, A. 2005. Optimization of methanol synthesis reactor using genetic algorithms. Chemical Engineering Journal, 108, 249-255.

KUMAR, V. \& REDDY, A. S. K. 2011. Why FCC riser is taller than model predictions? AIChE Journal, 57, 2917-2920.

LEE, L.-S., YU, S.-W., CHENG, C.-T. \& PAN, W.-Y. 1989. Fluidized-bed catalyst cracking regenerator modelling and analysis. The Chemical Engineering Journal, 40, 71-82.

LEÓN-BECERRIL, E., MAYA-YESCAS, R. \& SALAZAR-SOTELO, D. 2004. Effect of modelling pressure gradient in the simulation of industrial FCC risers. Chemical Engineering Journal, 100, 181-186. 
MA, C. G. \& WENG, H. X. 2009. Application of Artificial Neural Network in the Residual Oil Hydrotreatment Process. Petroleum Science and Technology, 27, 2075-2084.

MAO, X., WENG, H., ZHU, Z., WANG, S. \& ZHU, K. 1985. Investigation of the lumped kinetic model for catalytic cracking: III. Analyzing light oil feed and products and measurement of kinetic constants. Acta Pet. Sin. (Pet. Process Sect.), 1.

MU, S.-J., SU, H.-Y., LI, W. \& CHU, J. 2005. Reactor model for industrial residual fluid catalytic cracking based on six-lump kinetic model. Gao Xiao Hua Xue Gong Cheng Xue Bao/Journal of Chemical Engineering of Chinese Universities, 19, 630-635.

MUJTABA, I. M. 2012. Use of Various Computational Tools and gPROMS for Modelling Simulation Optimisation and Control of Food Processes. In: AHMED, J. \& RAHMAN, M. S. (eds.) Handbook of Food Process Design (1). Wiley-Blackwell.

MUSKE, K. R. \& RAWLINGS, J. B. 1995. Nonlinear moving horizon state estimation, Netherlands, Kluwer Academic Publisher.

NOWEE, S. M., ABBAS, A. \& ROMAGNOLI, J. A. 2007. Optimization in seeded cooling crystallization: A parameter estimation and dynamic optimization study. Chemical Engineering and Processing: Process Intensification, 46, 1096-1106.

QUANN, R. J. \& JAFFE, S. B. 1992. Structure-oriented lumping: describing the chemistry of complex hydrocarbon mixtures. Industrial \& Engineering Chemistry Research, 31, 2483-2497.

RÉGNIER, N., DEFAYE, G., CARALP, L. \& VIDAL, C. 1996. Software sensor based control of exothermic batch reactors. Chemical Engineering Science, 51, 5125-5136.

ROBERTSON, D. G., LEE, J. H. \& RAWLINGS, J. B. 1996. A Moving Horizon-Based Approach for Least-Squares Estimation A.I.Ch.E., 42, 2209-2224.

SA, Y., CHEN, X., LIU, J., WENG, H., ZHU, Z. \& MAO, X. 1985. Investigation of the lumped kinetic model for catalytic cracking and establishment of the physical model. Acta Pet. Sin. (Pet. Process Sect.), 1.

SADEGHBEIGI, R. 2000. Fluid Catalytic Cracking-HANDBOOK-Design, Operation and Troubleshooting of FCC Facilities, USA, Gulf Professional Publishing.

SOROUSH, M. 1997. Nonlinear state-observer design with application to reactors. Chemical Engineering Science, 52, 387-404.

SOROUSH, M. 1998. State and parameter estimations and their applications in process control. Computers \& Chemical Engineering, 23, 229-245.

SOUZA, J. A., VARGAS, J. V. C., ORDONEZ, J. C., MARTIGNONI, W. P. \& VON MEIEN, O. F. 2011. Thermodynamic optimization of fluidized catalytic cracking (FCC) units. International Journal of Heat and Mass Transfer, 54, 1187-1197.

SOUZA, J. A., VARGAS, J. V. C., VON MEIEN, O. F., MARTIGNONI, W. P. \& ORDONEZ, J. C. 2009. The inverse methodology of parameter estimation for model adjustment, design, simulation, control and optimization of fluid catalytic cracking (FCC) risers. Journal of Chemical Technology \& Biotechnology, 84, 343-355.

TAKATSUKA, T., SATO, S., MORIMOTO, Y. \& HASHIMOTO, H. 1987. A reaction model for fluidized-bed catalytic cracking of residual oil. Int Chem Eng, 27, 107-116.

TATIRAJU, S. \& SOROUSH, M. 1997. Nonlinear State Estimation in a Polymerization Reactor. Industria \& Engineering Chemistry Research, 36, 2679-2690.

TATIRAJU, S. \& SOROUSH, M. 1998. Parameter Estimator Design with Application to a Chemical Reactor. Ind. Eng. Chem. Res., 37, 455-463.

THEOLOGOS, K. N. \& MARKATOS, N. C. 1993. Advanced modeling of fluid catalytic cracking riser-type reactors. AIChE Journal, 39, 1007-1017.

TJOA, I. B. \& BIEGLER, L. T. 1992. Reduced successive quadratic programming strategy for errors-in-variables estimation. Computers \& Chemical Engineering, 16, 523-533. 
TSUO, Y. P. \& GIDASPOW, D. 1990. Computation of flow patterns in circulating fluidized beds. A.I.Ch.E., 36, 885.

WANG, L., YANG, B. \& WANG, Z. 2005. Lumps and kinetics for the secondary reactions in catalytically cracked gasoline. Chemical Engineering Journal, 109, 1-9.

WEEKMAN, V. W. J. 1968. A Model of Catalytic Cracking Conversion in Fixed, Moving, and Fluid-Bed Reactors. l\&EC Process Design and Development, 7, 90-95.

XIONG, K., LU, C., WANG, Z. \& GAO, X. 2015. Kinetic study of catalytic cracking of heavy oil over an in-situ crystallized FCC catalyst. Fuel, 142, 65-72.

XU, O.-G., SU, H.-Y., MU, S.-J. \& CHU, J. 2006. 7-lump kinetic model for residual oil catalytic cracking. Journal of Zhejiang University-SCIENCE A, 7, 1932-1941.

YOU, H. 2013. The Forecast of Nine Lumped Kinetic Models of FCC Gasoline Under Aromatization Reaction Conditions. Energy Sources, Part A: Recovery, Utilization, and Environmental Effects, 36, 54-63.

YOU, H., XU, C., GAO, J., LIU, Z. \& YAN, P. 2006. Nine lumped kinetic models of FCC gasoline under the aromatization reaction conditions. Catalysis Communications, 7, 554-558.

ZHANG, Y.-C., WANG, Z.-B., JIN, Y.-H., LI, Z.-H. \& YI, W.-M. 2017. Kinetic study of catalytic cracking on the effect of reaction parameters in short-contact cyclone reactors. Chemical Engineering Research and Design, 119, 188-197.

ZHU, K., MAO, X., WENG, H., ZHU, Z. \& LIU, F. 1985. Investigation of the lumped kinetic model for catalytic cracking: II. A prior simulation for experimental planning. Acfa Pet. Sin. (Pet. Process Sect.), 1.

916

917 